\title{
In Vitro Biological Screening for Antimicrobial, DNA Cleavage Anti-Diabetic, Antioxidant, Anti-Inflammatory and Antihaemolytic of Some Metallocephalosporins
}

\author{
Doaa.A.Ghareeb ${ }^{a}$, Mamdouh. S. Masoud ${ }^{b}$, Alaa. E. Ali ${ }^{\mathrm{c}, *}$, Hassan A.H. Ibrahim ${ }^{\text {, }}$ \\ Nessma. M. Nasr ${ }^{\mathrm{e}}$ \\ ${ }^{a}$ Biochemistry Department, Faculty of Science, Alexandria University, Alexandria, Egypt. \\ ${ }^{b}$ Chemistry Department, Faculty of Science, Alexandria University, Alexandria, Egypt. \\ ${ }^{c}$ Chemistry Department, Faculty of Science, Damanhour University, Damanhour, Egypt. \\ ${ }^{d}$ Marine Microbiology Department, Institute of Ochenography and Fishers, Alexandria, Egypt. \\ ${ }^{e}$ University Student's Hospital, Alexandria University, Alexandria, Egypt.
}

\begin{abstract}
In vitroantimicrobial activity, DNA cleavage, anti-diabetic, antioxidant, anti-inflammotary and antihaemolytic of some synthesized Metallocephradines and Metallocefepimes were examined. In a broadspectrum of antibacterial and antifungal property, it was found that nickel (1:1) and copper (1:2) complexes were more active than cephradine against all tested bacteria except S.pyogenes and E.fecalis. Metallocefepimesare potentially good inhibitors of the fungi. It was found that chromium (2:1) and cobalt (2:1) cefepime complexes exerted significant activity towards A.flavus. They were eight times $(M I C=0.49 \mu \mathrm{g} / \mathrm{ml})$ as active as the standard amphotericin $(M I C=3.9 \mu \mathrm{g} / \mathrm{ml})$. It was found that all Metallocephradines acts as maltase, lactase sucrase, amylase and lipase inhibitors, except Cu-cephradine (1:2) and mixed metal (Fe-Ni)-cephradine complexes did not show inhibitory effect on maltase. On the other hand, all Metallocefepimes act as maltase, lactase, sucrose and amylase inhibitors. So, the presence of metals caused a significant inhibition in comparison with cefepime and control. The activity of the complexes in scavenging of free radical DPPH is fairly good but less than ascorbic acid (113.91\%) as positive control, except Fe-cephradine complex in 2:1(M:L), which showed higher activity than ascorbic acid (124.90\%).Also, Metallocephradines and Metallocefepimes were examined for in vitro anti-inflammatoryactivity and toxicity by HRBC. Metallocephradines showed significant antiinflammatory activity and safe, where the hemolysis index $<5 \%$ in a concentration dependent manner, except $\mathrm{Ni}$ (II)-cephradine complex in 1:1 (M:L) ratio and Cr (III)-cefepime complex in 2:1 (M:L) ratio exhibited toxicity (hemolysis index $>5 \%$ ).
\end{abstract}

Keywords: Metallocephalosporins, Antimicrobial, Anti-diabetic, Antioxidant, Anti-inflammotary

\section{INTRODUCTION}

Drug development is the process by which drug companies test incipient molecules and assemble the obligatory evidence required by regulatory agencies to show that a drug is safe and efficacious. The development of incipient drug requires input from many diverse areas, such as biology, biochemistry, pharmacology, animal, toxicology, medical science and biostatics. The criteria for screening these molecules can be the results of in vitro cellular predicated screening assays that are designed to detect the properties that are potential to provide the clinical benefit [1]. The clinical development of incipient drugs traditionally takes place in three phases, the first phase is to identify the maximum tolerable dose, which is the highest dose of the study drug that is deemed tolerable for most subjects, while the second phase is quantifying the drug activity cognate to its potential clinical benefit across a range of factors that may modify the magnitude of the treatment effect, these factors include the dose of the drug or the type of disease. If the activity of the study drug looks promising in phase two, then the drug enters the third phase to develop evidence that the drug is safe enough to administer to the much wider population of patients that will receive it to once marketing approbation is granted [2].

Most drugs are organic or biologically derived compounds. After the discovery of the cisplatin, there is a growing interest in metal-containing drugs, and medicinal inorganic chemistry covering applications of metals in therapeutics and diagnostics [3]. Some of the metal-based drugs already in market are cisplatin (anticancer drug). Also, cardolite (myocardial imaging agent drug), silverderma 
(skin burn drugs marketed in spain by Aldo Union), flammazine (skin diseases drug marketed by Durpha) and matrix metalloproteinase inhibitors (cancer and inflammatory disease marketed by British Biotech) [4-6].

The term metalloantibiotic is given for metal complexes of antibiotics, which have potent antimicrobial activities and are utilized in medicinal field such as silver bandages for treatment of burns, zinc antiseptic creams, bismuth drugs for the treatment of ulcers and additionally as anti-HIV drugs.Albeit most antibiotics do not require metal ions for their biological activities but, there are some of antibiotics that require metal ions such as bleomycin, streptonigrin, and bacitracin.The antibiotic complexes can interact with several different kinds of biomolecules, including DNA, RNA, proteins, receptors, and lipids, rendering their unique and concrete bioactivities. In additament to antimicrobial activity of metalloantibiotics, antiviral and antineoplastic activities which provide a sundry function of these metalloantibiotics. Bismuth-fluoroquinolone complexes have developed as drugs against $H$. pylori cognate ailments. Antibiotics metal complexes and the commixed antibiotics metal complexes were found more efficacious as chemotherapy agents than their parent antibiotics [7$11]$.

Infectious diseases are caused by pathogenic microorganisms, such as bacteria, viruses, parasites or fungi. Many metal complexes have powerful antimicrobial activities and some of them are already in market such as silver bandages for treatment of burns. The discovery and development of effective antibacterial and antifungal drugs with novel mechanism of action has become an urgent task for infectious disease [12].

Diabetes mellitus (DM) is a condition characterized by abnormal glucose levels with a tendency to hyperglycemia due to a relative or absolute deficiency of insulin, which develops many secondary complications such as atherosclerosis, microangiopathy, renal dysfunction and failure, cardiac abnormality, diabetes retinopathy and ocular disorders. DM is classified as either insulin-dependent type 1 or non-insulin-dependent type 2, by the world health organization [13]. Although several types of insulin preparations for type 1 diabetes mellitus and those of synthetic drugs for type 2 diabetes mellitus have been developed and clinically used, they have several problems such as physical and mental pain due to daily insulin injections and defects involving side effects, respectively. So, a new class of pharmaceuticals should be introduced as a number of drugs are going off patent. For this reason, metallopharmaceuticals containing vanadium and zinc ions are expected to treat both types of diabetes mellitus such as vanadyl- and zinc-allixin complexes, which have been proposed to be the new candidates in treating diabetes mellitus [14-15]. Also, $\mathrm{Cu}$ (II) and $\mathrm{Zn}$ (II) ions and their complexes have been found to exhibit in vitro insulinomimetic activity and in vivo antidiabetic (both type-1 and 2) effects in animals [16-17]. The complexation of these ions with ligands having antidiabetic molecules as backbone has been found to exhibit many fold enhancement in the activity [18-19]. Also, insulinomimetic $\mathrm{Zn}$ (II) complexes with different coordination structures and with a blood glucose lowering effect to treat type 2 diabetes in animals were found [20].

Oxidative stress appears to be an important part of many human diseases; the use of antioxidants in pharmacology is intensively studied, particularly as treatments for stroke and neurodegenerative diseases. Moreover, oxidative stress is also the cause of diabetes mellitus [21-22]. Antioxidants are widely used in dietary supplements and have been investigated for the prevention of diseases such as cancer, coronary heart disease and even altitude sickness. Therefore there is a strong need of the design of novel potential therapeutic candidates for prevention the oxidative stress-related carcinogenesis based on metal complexes [23].

Inflammation is considered as a primary physiologic defense mechanism that helps body to protect itself against infection, burn, toxic chemicals and allergens. An uncontrolled and persistent inflammation may act as an etiologic factor for many of these chronic illnesses. Therefore, the development of potent anti-inflammatory drugs with fewer side effects is necessary [21]. $\mathrm{Cu}$ (II) complex of aspirin has been found about 30 times more effective than aspirin as an anti-inflammatory agent. In addition, $\mathrm{Cu}$ (II) complexes of many non-anti-inflammatory agents exhibited antiinflammatory action. The pharmacological activity of these complexes has been proposed to be due to its inherent physico-chemical properties of the complex itself rather than that of its constituents [22]. A large number of transition metal complexes of non-steroidal anti-inflammatorydrugs such as tolmetin, naproxen, ibuprofen, flufenamic acid, indomethacin, diclofenac, aspirin and piroxicam have been synthesized and tested for their anti- inflammatory effect. Some vanadyl complexes of antiinflammatory drugs containing carboxylate ligands have shown promising results [23]. 
In Vitro Biological Screening for Antimicrobial, DNA Cleavage Anti-Diabetic, Antioxidant, AntiInflammatory and Antihaemolytic of Some Metallocephalosporins

The aim of this study was to investigate the in vitro biological activities (antimicrobial, DNA cleavage, antidaibetic, antioxidant, anti-inflammotry and antihaemolytic) of Metallocephradines and Metallocefepimes.

\section{EXPERIMENTAL}

\subsection{Synthesis of Simple and Mixed Metallocephradines and Metallocefepimes}

The simple metal-cephradine and cefepime complexes were prepared by mixing molar amount of the metal salts $\mathrm{Cr}(\mathrm{III}), \mathrm{Mn}(\mathrm{II}), \mathrm{Fe}(\mathrm{III}), \mathrm{Co}(\mathrm{II}), \mathrm{Ni}(\mathrm{II}), \mathrm{Cu}(\mathrm{II}), \mathrm{Zn}$ (II), $\mathrm{Cd}(\mathrm{II})$ and $\mathrm{Hg}(\mathrm{II})$ as chloride dissolved in $10 \mathrm{ml}$ water with the calculated amount of the ligand, while the mixed metal cephradine complexes, $\mathrm{Fe}(\mathrm{III}) \mathrm{M}(\mathrm{II})$, where $[\mathrm{M}(\mathrm{II})=\mathrm{Cu}(\mathrm{II})$ or $\mathrm{Co}(\mathrm{II})]$ were prepared by dissolving $1 \mathrm{mmol}$ of $\mathrm{Fe}(\mathrm{III})$ and $1 \mathrm{mmol} \mathrm{Cu}$ (II) or $\mathrm{Co}(\mathrm{II})$ chloride in $10 \mathrm{ml}$ distilled water, then the resulting solution was added to cephradine $(1 \mathrm{mmol}$ in $10 \mathrm{ml})$, while the hetero cefepime complexes Fe(III)M(II), where $[\mathrm{M}(\mathrm{II})=\mathrm{Ni}(\mathrm{II})$ or $\mathrm{Cu}(\mathrm{II})]$ were prepared by dissolving $1 \mathrm{mmol}$ of $\mathrm{Fe}(\mathrm{III})$ and $1 \mathrm{mmol} \mathrm{Ni(II)}$ chloride or $\mathrm{Cu}$ (II) in $10 \mathrm{ml}$ , the resulting solution was then added to cefepime $(1 \mathrm{mmol}$ in $10 \mathrm{ml})$. The mixture was refluxed for about $5 \mathrm{~min}$. The complexes were precipitated and were filtered, then washed several times with a mixture of EtOH- $\mathrm{H}_{2} \mathrm{O}$ and dried in a desiccator over anhydrous $\mathrm{CaCl}_{2}$. The metal ion contents were determined by complexmetric titration procedures and atomic absorption spectroscopy. The halogen content was determined by titration with standard $\mathrm{Hg}\left(\mathrm{NO}_{3}\right)_{2}$ solution using diphenylcarbazone indicator [24-30]. The analytical data and physical properties of the studied compounds are represented in Table 1 as previously reported [10-11]. A representative example for the structure of cephradine and its iron complex was shown in Figure 1.

\subsection{Antimicrobial Activity}

Antimicrobial activity was determined using the agar well diffusion assay. The tested organisms, $S$. pyogenes, K. pneumoniae, $P$. mirabilis, E. fecalis, S. pneumoniae, $P$. aeruginosa, E. coli and $S$. aureus were subcultured on nutrient agar medium (Oxoid laboratories, UK) for bacteria and saboroud dextrose agar (Oxoid laboratories, UK) for fungi. Cephradine and cefepimewere used as a positive control for bacterial strains, Amphotericin B was used as a positive control for A. niger, A. flavus, $S$. racemosum, $C$. albicans, $C$. glabrata, $F$. oxysporum, $R$. solani and $A$. solani fungal strains, . The plates were done in triplicate. Bacterial cultures were incubated at $37^{\circ} \mathrm{C}$ for $24 \mathrm{~h}$, while the other fungal cultures were incubated at $25-30^{\circ} \mathrm{C}$ from three to seven days. Antimicrobial activity was determined by measurement zone of inhibition [31].

\subsection{Determination of MIC}

The minimum inhibitory concentration (MIC) of the samples was estimated for each of the tested organisms in triplicates. Varying concentrations of the samples $(1000-0.007 \mu \mathrm{g} / \mathrm{ml})$, nutrient broth were added and then a loopful of the test organism previously diluted to 0.5 McFarland turbidity standard was introduced to the tubes. A tube containing broth media only was seeded with the test organisms to serve as control. Tubes containing tested organisms cultures were then incubated at $37^{\circ} \mathrm{C}$ for $24 \mathrm{~h}$, while the other fungal cultures were incubated at $25-30^{\circ} \mathrm{C}$ from three to seven days. The tubes were then examined for growth by observing for turbidity [32].

\subsection{DNA Cleavage}

The DNA cleavage experiment was conducted using charge transfer DNA by gel electrophoresis with the corresponding metal complex in presence of $\mathrm{H}_{2} \mathrm{O}_{2}$ as an oxidant [33-34]. One mg of DNA $(0.1 \mu \mathrm{g})$ was dissolved in $10 \mathrm{ml}$ buffer $(50 \mathrm{mM}$ Tris-HCl-18 mM NaCl buffer $\mathrm{pH}=7.2)$, then $20 \mu \mathrm{l}$ was mixed with $2 \mu \mathrm{l}$ of compound and $10 \mu \mathrm{l}$ of $\mathrm{H}_{2} \mathrm{O}_{2}$ (4\%)and let to stand for $2.30 \mathrm{~h}$ in room temperature, after that the samples were electrophoreesed for $1 \mathrm{~h}$ at $80 \mathrm{~V}$ [35-38].

\subsection{Agarose Gel Electrophoresis Protocol}

Fifteen microliters of DNA samples mixed with loading buffer were loaded in $1 \%$ agarose in $1 \mathrm{x}$ TBE buffer containing $5 \mu \mathrm{l}$ ethidium bromide well and electrophoresed at 100v for $1 \mathrm{~h}$. DNA bands were visualized using UV transmitter [35-38].

\subsection{Determination of (Lactase, Sucrase and Maltase) Activity}

Ten microliterspencreatine $\left(0.1 \mathrm{~g} / 10 \mathrm{ml} \mathrm{H}_{2} \mathrm{O}\right.$ containing drops of $\left.\mathrm{NaOH}\right)$ was mixed with $5 \mu \mathrm{l}$ of compound and $50 \mu \mathrm{l}$ phosphate buffer $(\mathrm{pH}=7.4)$, the mixturewas incubated for $45 \mathrm{~min}$, then $10 \mu \mathrm{l}$ of substrate lactose or maltose or sucrose $(1 \mathrm{~g} \%)$ was added and the mixture was incubated for $20 \mathrm{~min}$. The reaction was stopped by thermal denaturation then $100 \mu \mathrm{l}$ of glucose reagent was added to the previous mixture and incubated for $20 \mathrm{~min}$ at room temperature. Absorbance at 450nm was read [39]. 
Specific activity of (lactase, sucrase and maltase) was reported as $U=\mu \mathrm{g}$ of glucose $\mathrm{min}^{-1} \mathrm{mg}^{-1}$ of protein.

\subsection{Estimation of $\alpha$-Amylase Activity}

Twentymicrolitersamylase $(1 \mathrm{~g} \%)$ was mixed with $5 \mu \mathrm{l}$ of compound and $100 \mu \mathrm{l}$ phosphate buffer $(\mathrm{pH}=6.9)$, then the mixturewas left for $45 \mathrm{~min}$ at room temperature. After incubation, $20 \mu \mathrm{l}$ of substrate soluble starch $(1 \mathrm{~g} \%)$ was added and the mixture was incubated for $20 \mathrm{~min}$, then $100 \mu \mathrm{l}$ of glucose reagent was added to the previous mixture and incubated for $20 \mathrm{~min}$. Absorbance was read at $490 \mathrm{~nm}[40-41]$.

Specific activity of amylase is reported as $\mathrm{U}=\mu \mathrm{g}$ of maltose $\mathrm{min}^{-1} \mathrm{mg}^{-1}$ of protein

\subsection{Determination of Lipase Activity}

$0.5 \mathrm{ml}$ lipase $(1 \mathrm{~g} \%)$ enzyme was mixed with $2.5 \mathrm{ml}$ olive (100ml olive oil +2 Bitterness bass) and 1.25 $\mathrm{ml} 0.2 \mathrm{M}$ tris buffer $(\mathrm{pH}=8)$, then the mixturewas incubated for $2 \mathrm{hr}$ at $37^{\circ} \mathrm{C}$. At the end of incubation, $1.5 \mathrm{ml}$ of ethanol was added. Fatty acids liberated during the reaction were titrated with $0.2 \mathrm{M} \mathrm{NaOH}$ using ph.ph as an indicator. The color changes from colorless to pink [42].

Specific lipase activity is reported as $\mathrm{U}=\mu \mathrm{l}$ of $0.2 \mathrm{M} \mathrm{NaOH} \mathrm{mg}^{-1}$ of protein.

\subsection{Determination of Antioxidant Activity}

For the determination of scavenging activity of $0.135 \mathrm{mM}$ DPPH free radical in the synthesized compounds, $0.135 \mathrm{mM}$ DPPH in methanol was prepared and $100 \mu \mathrm{l}$ of this solution was mixed with $100 \mu \mathrm{l}$ of compounds containing $20-100 \mu \mathrm{g} / \mathrm{ml}$ and standard antibiotics. The reaction mixture was left in the dark at room temperature for $30 \mathrm{~min}$. the absorbance of the mixture was measured spectrophotometrically at $517 \mathrm{~nm}$ [43]. The ability of compounds to scavenge DPPH radical was calculated by the equation:

DPPH radical scavenging activity $=\frac{\mathrm{A}_{\text {control }}}{\mathrm{A}_{\text {sample }}} \times 100$

\subsection{Preparation of Liver Homogenate}

Fresh liver was removed immediately, washed with cold saline solution $(0.9 \% \mathrm{NaCl})$, weighed, then homogenized in five volume of cold $0.1 \mathrm{M}$ sodium phosphate buffer containing $0.9 \% \mathrm{NaCl}(\mathrm{pH} 7.4$ ) using a glass-Teflon homogenizer. All processes were carried out at $4{ }^{\circ} \mathrm{C}$ and used as enzyme source for DPPH reductase activity [44].

\subsection{The Effect of Synthesized Compounds on DPPH-Reductase Activity}

Fiftymicrolitersof liver homogenate was added to10 $\mu$ of compoundand then the mixturewas incubated for $45 \mathrm{~min}$. After incubation, $50 \mu \mathrm{l}$ of $300 \mu \mathrm{M}$ DPPH, $50 \mu \mathrm{l}$ of $100 \mu \mathrm{M}$ NADPH and $50 \mu 1$ of $0.1 \mathrm{M}$ phosphate buffer $(\mathrm{pH}=7.6)$ were added to the previous mixture and leave it in $20 \mathrm{~min}$ incubation. Read the absorbance at $520 \mathrm{~nm}$ [45].

An extinction coefficient of $4.09 \mathrm{mM}^{-1} \mathrm{~cm}^{\square}$ was used to calculate the number of moles of DPPH reduced per mol of enzyme.

\subsection{Anti-Inflammatory Activity}

$20 \mu \mathrm{l}$ of $10 \mathrm{Mm}$ sodium nitroprusside was added to $5 \mu \mathrm{l}$ phosphate buffer and $5 \mu \mathrm{l}$ of the complex solution. The mixture was incubated at $25^{\circ} \mathrm{C}$ for 2.5 hours. After incubation, $20 \mu \mathrm{l}$ of Griess reagent (1gm of sulphanilic acid+0.1gm naphthylethylene diamine dihydrochloride) was added to the previous mixture and allowed to stand for 30 minutes at room temperature. The absorbance was read at $540 \mathrm{~nm}$ [46].

Nitric oxide scavenging activity $=\frac{\mathrm{A}_{\text {control }}-\mathrm{A}_{\text {sample }}}{\mathrm{A}_{\text {control }}} \times 100$

\subsection{Cytoxicity Study on Human Red Blood Corpuscles (HRBCs) Membrane Stabilizing}

This method is based on the measurement of light absorbance $(\mathrm{Ab})$ at $450 \mathrm{~nm}$ of erythrocyte hemoglobin whose reaction yield is enhanced/ inhibited through the agency of new material that used as a starter /inhibitor for the peroxide oxidation of lipids in erythrocytic membranes [33]. The blood was collected from healthy human volunteer who had not taken any anti-inflammatory drugs for 2 weeks prior to the experiment and transferred to the centrifuge at $3000 \mathrm{rpm}$. The packed cells were washed with saline and a $10 \%$ suspension in normal saline was made. The reaction mixture $4-5 \mathrm{ml}$ 
In Vitro Biological Screening for Antimicrobial, DNA Cleavage Anti-Diabetic, Antioxidant, AntiInflammatory and Antihaemolytic of Some Metallocephalosporins

consisted $2 \mathrm{ml}$ of hypotonic saline $(0.25 \% \mathrm{w} / \mathrm{v} \mathrm{NaCl}), 1 \mathrm{ml}$ of $0.15 \mathrm{M}$ phosphate buffer $(\mathrm{pH} 7.4)$ and 1 $\mathrm{ml}$ of compounds solution $(1 \mathrm{mg} / \mathrm{ml})$ in normal saline and $0.5 \mathrm{ml}$ of $10 \% \mathrm{HRBC}$ in normal saline. For control, $1 \mathrm{ml}$ of isotonic saline was used instead of compounds solution. The mixtures were incubated at $56^{\circ} \mathrm{C}$ for $30 \mathrm{~min}$ and cooled at running tap water, centrifuge at $3000 \mathrm{rpm}$ for $20 \mathrm{~min}$. The absorbance of supernatant was read at $560 \mathrm{~nm}$ using visible spectrophotometer [33]. The experiment was performed in triplicates. The control represents $100 \%$ lyses.Stock solution of compounds $(1 \mathrm{mg} / \mathrm{ml})$ and (serial dilutions: $500,100,10,5 \mu \mathrm{g} / \mathrm{mL})$ until obtaining the safe dose. The percentage membrane stabilization was calculated using the following formula:

Degree of hemolysis $(\%)=\left[\frac{\text { Test }- \text { Blank }}{\text { Emax }}\right] \times 100$
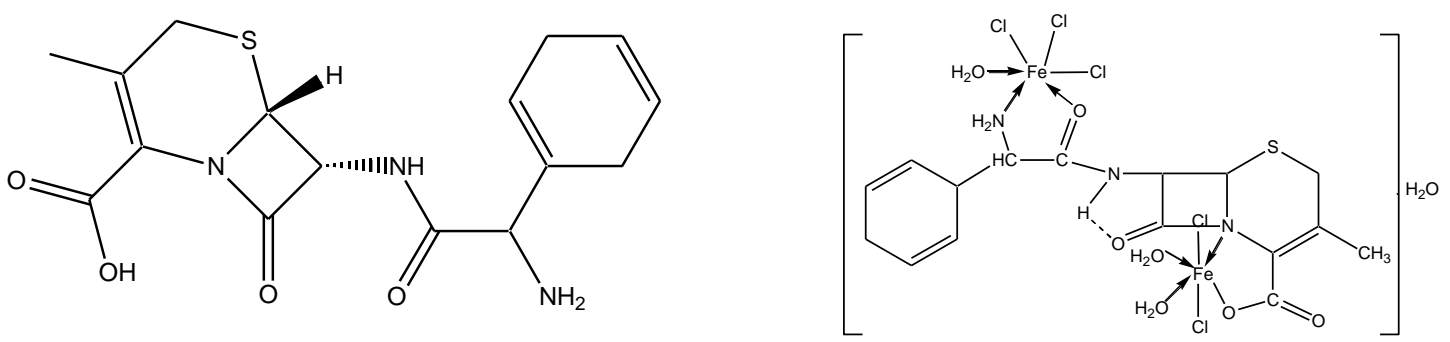

Figure1. The structure of cephradine and its iron complex

Table1. Analytical data, effective magnetic moment $\mu_{\text {eff }}$ and geometry of Metallocephradines, and Metallocefepimes

\begin{tabular}{|c|c|c|c|c|c|}
\hline \multirow[t]{2}{*}{ NNo. } & \multirow{2}{*}{ Compounds } & \multicolumn{2}{|c|}{$\%$ Found (\% Calculated) } & \multirow{2}{*}{$\mu_{\text {eff }}$} & \multirow{2}{*}{ Geometry } \\
\hline & & $\mathbf{M}$ & $\mathrm{Cl}$ & & \\
\hline 1 & {$\left[\mathrm{Cr}_{2}(\text { Cephradine })_{3}(\mathrm{OH})_{3} \mathrm{H}_{2} \mathrm{O}\right] 3 \mathrm{H}_{2} \mathrm{O}$} & $8.1(8.0)$ & - & 3.91 & $\mathrm{O}_{\mathrm{h}}$ \\
\hline 2 & {$\left[\mathrm{Mn}(\right.$ Cephradine $\left.) \mathrm{Cl}\left(\mathrm{H}_{2} \mathrm{O}\right)_{3}\right] \mathrm{HCl} \cdot 2 \mathrm{H}_{2} \mathrm{O}$} & $9.7(9.7)$ & $12.5(12.1)$ & 3.92 & $\mathrm{O}_{\mathrm{h}}$ \\
\hline 3 & {$\left[\mathrm{Fe}_{2}(\right.$ Cephradine $\left.) \mathrm{Cl}_{5}\left(\mathrm{H}_{2} \mathrm{O}\right)_{3}\right] \mathrm{H}_{2} \mathrm{O}$} & $15.7(15.9)$ & $24.8(24.3)$ & 11.8 & $\mathrm{O}_{\mathrm{h}}$ \\
\hline 4 & {$\left[\mathrm{Co}(\text { Cephradine })_{3}\right] 2 \mathrm{HCl} . \mathrm{H}_{2} \mathrm{O}$} & $4.9(4.9)$ & $5.9(5.9)$ & 5.2 & $\mathrm{O}_{\mathrm{h}}$ \\
\hline 5 & {$\left[\mathrm{Ni}\right.$ (Cephradine) $\left.\mathrm{ClH}_{2} \mathrm{O}\right] \mathrm{HCl} .3 \mathrm{H}_{2} \mathrm{O}$} & $10.6(10.6)$ & $12.8(12.9)$ & Diamagnetic & S.P \\
\hline 6 & $\left.[\mathrm{Ni} \text { (Cephradine })_{2}\right] 2 \mathrm{HCl}$ & $7.1(7.3)$ & $8.5(8.7)$ & Diamagnetic & S.P \\
\hline 7 & $\left.[\mathrm{Cu} \text { (Cephradine })_{2}\right] 2 \mathrm{HCl} .6 \mathrm{H}_{2} \mathrm{O}$ & $6.7(6.3)$ & $7.5(7.6)$ & 1.73 & S.P \\
\hline 8 & {$\left[\mathrm{Cu}_{3}(\right.$ Cephradine $\left.) 5 \mathrm{Cl} \mathrm{H} \mathrm{H}_{2} \mathrm{O}\right] \mathrm{HCl}$} & $24.7(24.8)$ & $27.6(27.7)$ & 5.25 & S.P \\
\hline 9 & {$\left[\mathrm{Zn}_{2}(\right.$ Cephradine $\left.) \mathrm{Cl}_{3} \mathrm{H}_{2} \mathrm{O}\right] \mathrm{HCl} . \mathrm{H}_{2} \mathrm{O}$} & $19.8(19.8)$ & $21.5(21.6)$ & Diamagnetic & $T_{d}$ \\
\hline 10 & {$\left[\mathrm{Cd}_{2}(\right.$ Cephradine $\left.) \mathrm{Cl}_{3} \mathrm{H}_{2} \mathrm{O}\right] \mathrm{HCl} . \mathrm{H}_{2} \mathrm{O}$} & $29.9(29.8)$ & $9.4(9.5)$ & Diamagnetic & $T_{d}$ \\
\hline 11 & {$\left[\mathrm{Hg}(\text { Cephradine })_{3}\right] 2 \mathrm{HCl} .6 \mathrm{H}_{2} \mathrm{O}$} & $14.1(14.0)$ & $4.9(5.1)$ & Diamagnetic & $\mathrm{T}_{\mathrm{d}}$ \\
\hline 12 & {$\left[\mathrm{Fe} \mathrm{Cu}_{2}(\text { Cephradine })_{2} \mathrm{Cl}_{5} \mathrm{H}_{2} \mathrm{O}\right] 2 \mathrm{HCl} .3 \mathrm{H}_{2} \mathrm{O}$} & $\begin{array}{c}\mathrm{Fe} 4.6(4.4) \\
\mathrm{Cu} 10.5(10.8)\end{array}$ & $20.6(20.7)$ & 9.38 & \begin{tabular}{|l}
$\mathrm{Fe} \mathrm{O}_{\mathrm{h}}$ \\
$\mathrm{Cu} \mathrm{S.P}$
\end{tabular} \\
\hline 13 & {$\left[\mathrm{Fe} \mathrm{Co}(\text { Cephradine })_{2} \mathrm{Cl}_{3} \mathrm{H}_{2} \mathrm{O}\right] 2 \mathrm{HCl} .3 \mathrm{H}_{2} \mathrm{O}$} & $\begin{array}{l}\text { Fe } 5.2(5.7) \\
\text { Co } 5.5(5.1)\end{array}$ & $16.6(16.8)$ & 11.12 & $\begin{array}{l}\mathrm{Fe} \mathrm{O}_{\mathrm{h}} \\
\mathrm{Co}_{\mathrm{d}}\end{array}$ \\
\hline 14 & {$\left[\mathrm{Fe} \mathrm{Ni}(\right.$ Cephradine $\left.) \mathrm{Cl}_{4}\left(\mathrm{H}_{2} \mathrm{O}\right)_{2}\right] \mathrm{HCl} .4 \mathrm{H}_{2} \mathrm{O}$} & $\begin{array}{l}\text { Fe } 7.4(7.3) \\
\text { Co } 7.8(7.7)\end{array}$ & $23.6(23.7)$ & 5.92 & $\begin{array}{l}\mathrm{Fe} \mathrm{O}_{\mathrm{h}} \\
\text { Ni S.P }\end{array}$ \\
\hline 15 & {$\left[\mathrm{Cr}_{2}(\right.$ Cefepime $\left.)(\mathrm{OH})_{4}\left(\mathrm{H}_{2} \mathrm{O}\right)_{4}\right] \mathrm{OH}_{2} \mathrm{H}_{2} \mathrm{O}$} & $13.7(13.6)$ & $4.1(4.2)$ & 3.87 & $\mathrm{O}_{\mathrm{h}}$ \\
\hline 16 & {$\left[\mathrm{Mn}_{2}(\text { Cefepime })_{3}(\mathrm{OH})_{2}\left(\mathrm{H}_{2} \mathrm{O}\right)_{2}\right](\mathrm{OH})_{3}$} & $6.5(6.7)$ & - & 11.8 & $\mathrm{O}_{\mathrm{h}}$ \\
\hline 17 & {$\left[\mathrm{Fe}(\text { Cefepime })_{3}\right] \mathrm{Cl}_{3} 4 \mathrm{H}_{2} \mathrm{O}$} & $3.2(3.1)$ & $6.2(6.3)$ & 5.95 & $\mathrm{O}_{\mathrm{h}}$ \\
\hline 18 & $[\mathrm{Fe}($ Cefepime $\left.)] \mathrm{Cl}_{2}\left(\mathrm{H}_{2} \mathrm{O}\right)_{2}\right] \mathrm{Cl} .3 \mathrm{H}_{2} \mathrm{O}$ & $7.6(7.4)$ & $31.1(31.2)$ & 7.80 & $\mathrm{O}_{\mathrm{h}}$ \\
\hline 19 & {$\left[\mathrm{Co}_{2}(\right.$ Cefepime $\left.)(\mathrm{OH})_{3} \mathrm{H}_{2} \mathrm{O}\right](\mathrm{OH})$} & $17.2(17.4)$ & - & 7.80 & $\mathrm{~T}_{\mathrm{d}}$ \\
\hline 20 & [Ni (Cefepime) $\left.\mathrm{Cl} \mathrm{H}_{2} \mathrm{O}\right] \mathrm{Cl} .5 \mathrm{H}_{2} \mathrm{O}$ & $8.1(7.9)$ & $9.8(9.9)$ & Diamagnetic & S.P \\
\hline 21 & {$\left[\mathrm{Ni}(\text { Cefepime })_{2}\right] \mathrm{Cl}_{2} \cdot 6 \mathrm{H}_{2} \mathrm{O}$} & $4.9(5.0)$ & $5.9(6.0)$ & Diamagnetic & S.P \\
\hline 22 & {$\left[\mathrm{Cu}(\text { Cefepime })_{3}\right] \mathrm{Cl}_{2} \cdot \mathrm{OH}$} & $3.9(4.1)$ & $4.4(4.5)$ & 1.73 & $\mathrm{O}_{\mathrm{h}}$ \\
\hline 23 & {$\left[\mathrm{Zn}(\right.$ Cefepime $\left.) \mathrm{Cl} \mathrm{H} \mathrm{H}_{2} \mathrm{O}\right] .5 \mathrm{H}_{2} \mathrm{O}$} & $9.0(8.9)$ & $9.7(9.6)$ & Diamagnetic & $\mathrm{T}_{\mathrm{d}}$ \\
\hline 24 & {$\left[\mathrm{Cd}(\right.$ Cefepime $\left.) \mathrm{OH} \mathrm{H}_{2} \mathrm{O}\right] \mathrm{OH}$} & $17.4(18.0)$ & - & Diamagnetic & $\mathrm{T}_{\mathrm{d}}$ \\
\hline 25 & {$\left[\mathrm{Hg}(\text { Cefepime })_{2}\right] \mathrm{Cl}_{2} \cdot 6 \mathrm{H}_{2} \mathrm{O}$} & $14.9(14.8)$ & $5.2(5.3)$ & Diamagnetic & $\mathrm{T}_{\mathrm{d}}$ \\
\hline 26 & {$\left[\mathrm{Fe} \mathrm{Cu}(\right.$ Cefepime $\left.) \mathrm{Cl}_{4}\left(\mathrm{H}_{2} \mathrm{O}\right)_{2}\right] \mathrm{Cl} \cdot 6 \mathrm{H}_{2} \mathrm{O}$} & $\begin{array}{l}\mathrm{Fe} 6.3(6.3) \\
\mathrm{Cu} 7.1(7.2) \\
\end{array}$ & $20.0(20.1)$ & 7.65 & $\begin{array}{l}\mathrm{Fe} \mathrm{O}_{\mathrm{h}} \\
\mathrm{Cu} \text { S.P }\end{array}$ \\
\hline 27 & {$\left[\mathrm{Fe} \mathrm{Ni}(\text { Cefepime })_{3} \mathrm{Cl}_{2}\right] \mathrm{Cl}_{3} \cdot 2 \mathrm{H}_{2} \mathrm{O}$} & $\begin{array}{l}\mathrm{Fe} 3.1(3.2) \\
\mathrm{Ni} 3.2(3.3) \\
\end{array}$ & $9.9(10.1)$ & 5.92 & \begin{tabular}{|l|}
$\mathrm{Fe} \mathrm{O} \mathrm{O}_{\mathrm{h}}$ \\
$\mathrm{Ni} \mathrm{S.P}$ \\
\end{tabular} \\
\hline 28 & {$\left[\mathrm{Co} \mathrm{Cu}_{3}\right.$ (Cefepime) $\left.\mathrm{Cl}_{7} \mathrm{H}_{2} \mathrm{O}\right] \mathrm{Cl} .3 \mathrm{H}_{2} \mathrm{O}$} & $\begin{array}{c}\text { Co } 5.4(5.4) \\
\mathrm{Cu} 17.5(17.6) \\
\end{array}$ & $26.1(26.2)$ & 9.84 & $\begin{array}{l}\text { Co } T_{d} \\
\text { Cu S.P }\end{array}$ \\
\hline
\end{tabular}




\section{RESULTS AND DISCUSSION}

\subsection{Antimicrobial Examination}

\subsubsection{Antibacterial Activity}

The in vitro antimicrobial screening of cephradine, cefepime and their complexes were performed against the following bacterial strains, S.pyogenes, K.pneumoniae, P.mirabilis, E.fecalis , S.pneumoniae, P.aeruginosa, E.coli and S.aureusand their efficiency against the bacteria was compared with the standard cephradine and cefepime, Table 2 . The minimum inhibitory concentration (MIC) of some selected complexes, which showed significant activity against selected bacterial species, was determined in comparison to the standard antibiotic cephradine are summarised in Table 3 . The values indicate that the complexes are potentially good inhibitors of the bacterial organisms. It was found that, the chromium complex against K.pneumoniae, P.mirabilis, E.coli and S.aureus was found to be having potentially enhanced antibacterial activities as compared to the standard drug. In a broad-spectrum of the bio-potential property, the iron (2:1), copper (3:1), nickel (1:2), zinc and the mixed metal iron-cobalt (1:1:2) complexes were efficient than cephradine . among these synthesized complexes, it was found that nickel (1:1) and copper (1:2) complexes were more active than cephradine against all tested bacteria except S.pyogenes and E.fecalis. On the other hand, cadmium had similar activty to the standard antibiotic. On the contrary, manganese (1:1), cobalt (1:3) and the mixed metal iron-copper (1:2:2) were not up to the standard against the bacterial strains.

In general, some Metallocephradines were found to be enforced potentially with the cephradine against the same micro-organisms and under the identical experimental conditions. The increase in efficiency of the metal complexes was due to the participation of metal ion on the demolition of bacterial cell process. The process of complexation reduces the polarity of the metal ion, because of partial sharing of its positive charge with the donor group (ligand)and the electrons delocalized within the metal-ligand complex system. Thus, the complexation favours permeation of the metal through the lipid layers of the microbes'cell membrane. Furthermore, the metal complexes form a hydrogen bond with the active centres of organism'scell constituents resulting in the perturbation of the normal cell respiratory process of the microbe. Thus, the complexation enhances the penetration and hence the rate of uptake/entrance of the metal into microbial cell and thus able to kill it [47].

Also, the higher aggressiveness of zinc (II)complex relative to the rest of the complexes was related to the difference in the effective nuclear charge. During complexation, the decreasing effective nuclear charge (polarity) of the Zn (II) is higher compared to other complexes, which in turn increases the lipophilicity and hence its penetration [48].

However, nickel (1:2), copper (1:4) and iron-copper (1:1:1) cefepime complexes showed a promising activity higher than the standard antibiotic cefepime. In addition, cobalt (2:1) complex exerted significant activity towords S.pyogenes and K.pneumoniae. It was eight times (MIC $=0.49 \mu \mathrm{g} / \mathrm{ml}$ ) as active as cefepime (MIC=3.9 $\mu \mathrm{g} / \mathrm{ml})$. In addition, nickel (1:2), copper (4:1) and the mixed metal ironcopper (1:1:1), while, the rest of Metallocefepimes were less active than the reference. The variation in the activity of different complexes against different organisms depends either on the impermeability of the cells of the microbes or on differences in ribosome of microbial cells. The increasing in the activity of the complexes was due to the coordination of metal ion to the antibiotic enhance the lipophilic character of the central metal atom [47-49].Generally, metal complexes are more active than the ligands because metal complexes may serve as a vehicle for activation of ligands as the principal cyctotoxic species.

\subsubsection{Antifungal Activity}

Antifungal activity of cephradine, cefepime and their metal complexes were examined against A.niger, A.flavus, S.racemosum, C.albicans, C.glabrata, F.oxysporum, R.solani and A.solani fungal strains and illustrated in Table 3. The minimum inhibitory concentration (MIC) of some selected complexes, which showed significant activity against selected fungi species, was determined in comparison to the standard antibiotic cephradine are summarized in Table 4 . The values indicate that the complexes are potentially good inhibitors of the fungi organisms. It was found that chromium (2:1) and nickel (1:1) complexes exerted significant activity towards A.flavus. They were four times (MIC $=0.98 \mu \mathrm{g} / \mathrm{ml}$ ) as active as the standard amphotericin $(\mathrm{MIC}=3.9 \mu \mathrm{g} / \mathrm{ml})$, while iron $(2: 1)$ complex showed activity against A.flavus two times (MIC $=1.95 \mu \mathrm{g} / \mathrm{ml}$ ) as active as the reference. On the other 
In Vitro Biological Screening for Antimicrobial, DNA Cleavage Anti-Diabetic, Antioxidant, AntiInflammatory and Antihaemolytic of Some Metallocephalosporins

hand, mercury (1:3) complex exhibited activity against A.niger four times (MIC $=0.12 \mu \mathrm{g} / \mathrm{ml}$ ) as active as amphotericin ( $\mathrm{MIC}=0.49 \mu \mathrm{g} / \mathrm{ml}$ ) and also exerted activity against A.flavus sixteen times $(\mathrm{MIC}=0.24 \mu \mathrm{g} / \mathrm{ml})$ as active as amphotericin.It was observed that all Metallocephradines have a promising antifungal activity rather than cephradine. The higher activity of the metal complexes may be due to the chelation reduces the polarity of the metal atom mainly because of partial sharing of its positive charge with donor groups and possible electron delocalization over the entire ring. This consequently increases the lipophilic character of the chelates, favoring their permeation through the lipid layers of the bacterial membrane [50-51].

Metallocefepimes are potentially good inhibitors of the fungi organisms. It was found that chromium (2:1) and cobalt (2:1) cefepime complexes exerted significant activity towards A.flavus. They were eight times $(\mathrm{MIC}=0.49 \mu \mathrm{g} / \mathrm{ml}$ ) as active as the standard amphotericin $(\mathrm{MIC}=3.9 \mu \mathrm{g} / \mathrm{ml})$, while coppercefepime complex (1:2) showed activity against A.flavus two times (MIC $=1.95 \mu \mathrm{g} / \mathrm{ml}$ ) as active as the reference. Also, cadmium cefepime complex (1:1) exhibited activity against A.flavus four times $(\mathrm{MIC}=0.98 \mu \mathrm{g} / \mathrm{ml})$ as active as amphotericin $(\mathrm{MIC}=0.49 \mu \mathrm{g} / \mathrm{ml})$.

Most of Metallocefepimes have a promising antifungal activity rather than cefepime, due to the chelation increases the lipophilic character of the chelates, favoring their permeation through the lipid layers of the bacterial membrane [50-51].

Table2. Antibacterial activity of Metallocephradines and Metallocefepimes

\begin{tabular}{|c|c|c|c|c|c|c|c|c|}
\hline Compounds & S.pyogenes & $\begin{array}{l}\text { K.pneumo } \\
\text { niae }\end{array}$ & P.mirabilis & E.fecalis & \begin{tabular}{|l|} 
S.pneumo \\
niae
\end{tabular} & \begin{tabular}{|l|} 
P.aerugin \\
osa
\end{tabular} & E.coli & S.aureus \\
\hline $\begin{array}{l}\text { Cephradine } \\
\text { standard }\end{array}$ & $20.6 \pm 0.44$ & $16.3 \pm 0.19$ & $15.8 \pm 0.25$ & $19.6 \pm 0.44$ & $20.4 \pm 0.44$ & NA & $17.3 \pm 0.25$ & $20.3 \pm 0.25$ \\
\hline $\begin{array}{l}{\left[\mathrm{Cr}_{2}(\text { Cephradine })_{3}\right.} \\
\left.(\mathrm{OH})_{3} \mathrm{H}_{2} \mathrm{O}\right] 3 \mathrm{H}_{2} \mathrm{O}\end{array}$ & $18.2 \pm 0.58$ & $20.9 \pm 0.63$ & $17.2 \pm 0.44$ & $16.4 \pm 0.63$ & $20.3 \pm 0.58$ & NA & $19.6 \pm 0.58$ & $20.9 \pm 0.63$ \\
\hline $\begin{array}{l}{[\mathrm{Mn}(\mathrm{Cephradine})} \\
\left.\mathrm{Cl}\left(\mathrm{H}_{2} \mathrm{O}\right)_{3}\right] \\
\mathrm{HCl} .2 \mathrm{H}_{2} \mathrm{O}\end{array}$ & $11.6 \pm 0.58$ & $12.9 \pm 0.44$ & NA & NA & $14.1 \pm 0.44$ & NA & NA & $14.6 \pm 0.58$ \\
\hline $\begin{array}{l}{\left[\mathrm{Fe}_{2}(\mathrm{Cephradine})\right.} \\
\left.\mathrm{Cl}_{5}\left(\mathrm{H}_{2} \mathrm{O}\right)_{3}\right] \mathrm{H}_{2} \mathrm{O}\end{array}$ & $21.3 \pm 0.63$ & $22.6 \pm 0.63$ & $19.8 \pm 0.44$ & $18.4 \pm 0.63$ & $21.9 \pm 0.37$ & NA & $22.8 \pm 0.44$ & $21.9 \pm 0.58$ \\
\hline $\begin{array}{l}{[\mathrm{Co}} \\
\left.(\text { Cephradine })_{3}\right] \\
2 \mathrm{HCl} . \mathrm{H}_{2} \mathrm{O}\end{array}$ & $13.6 \pm 0.44$ & $14.5 \pm 0.63$ & NA & $\mathrm{NA}$ & $15.2 \pm 0.63$ & NA & NA & $15.9 \pm 0.58$ \\
\hline $\begin{array}{l}\mathrm{Ni} \text { (Cephradine) } \\
\left.\mathrm{ClH}_{2} \mathrm{O}\right] \mathrm{HCl} \cdot 3 \mathrm{H}_{2} \mathrm{O}\end{array}$ & $20.3 \pm 0.58$ & $21.2 \pm 0.58$ & $18.4 \pm 0.63$ & $19.6 \pm 0.37$ & $22.9 \pm 0.82$ & $18.9 \pm 1.2$ & $22.6 \pm 0.58$ & $21.4 \pm 0.95$ \\
\hline $\begin{array}{l}{[\mathrm{Ni}} \\
\left.(\mathrm{Cephradine})_{2}\right] \\
2 \mathrm{HCl} .\end{array}$ & $23.6 \pm 0.58$ & $18.4 \pm 0.25$ & $18.6 \pm 0.37$ & $24.8 \pm 0.22$ & $23.9 \pm 0.63$ & NA & $19.6 \pm 0.25$ & $23.1 \pm 0.58$ \\
\hline $\begin{array}{l}{[\mathrm{Cu}} \\
\left.(\mathrm{Cephradine})_{2}\right] \\
2 \mathrm{HCl} .6 \mathrm{H}_{2} \mathrm{O}\end{array}$ & $20.6 \pm 0.58$ & $21.4 \pm 0.58$ & $18.6 \pm 0.58$ & $17.2 \pm 0.63$ & $20.5 \pm 0.44$ & NA & $21.3 \pm 0.44$ & $21.4 \pm 0.58$ \\
\hline $\begin{array}{l}{\left[\mathrm{Cu}_{3}(\mathrm{Cephradine})\right.} \\
\left.5 \mathrm{Cl} \mathrm{H} \mathrm{H}_{2} \mathrm{O}\right] \mathrm{HCl}\end{array}$ & $23.2 \pm 0.44$ & $19.3 \pm 0.58$ & $17.9 \pm 0.63$ & $24.2 \pm 0.25$ & $23.4 \pm 0.44$ & NA & $18.9 \pm 0.63$ & $22.9 \pm 0.25$ \\
\hline $\begin{array}{l}{\left[\mathrm{Zn}_{2}(\text { Cephradine })\right.} \\
\left.\mathrm{Cl}_{3} \mathrm{H}_{2} \mathrm{O}\right] \mathrm{HCl} \\
. \mathrm{H}_{2} \mathrm{O}\end{array}$ & $23.5 \pm 0.63$ & $25.2 \pm 0.14$ & $20.7 \pm 0.58$ & $20.1 \pm 0.63$ & $24.2 \pm 0.44$ & $20.3 \pm 0.44$ & $24.5 \pm 0.44$ & $23.9 \pm 0.58$ \\
\hline $\begin{array}{l}{\left[\mathrm{Cd}_{2}(\text { Cephradine })\right.} \\
\left.\mathrm{Cl}_{3} \mathrm{H}_{2} \mathrm{O}\right] \mathrm{HCl} \\
. \mathrm{H}_{2} \mathrm{O}\end{array}$ & $20.6 \pm 0.44$ & $16.3 \pm 0.19$ & $15.8 \pm 0.25$ & $19.6 \pm 0.44$ & $20.4 \pm 0.44$ & NA & $17.3 \pm 0.25$ & $20.3 \pm 0.25$ \\
\hline $\begin{array}{l}{[\mathrm{Hg}} \\
\left.(\text { Cephradine })_{3}\right] \\
2 \mathrm{HCl} .6 \mathrm{H}_{2} \mathrm{O}\end{array}$ & $22.3 \pm 0.63$ & $22.99 \pm 0.58$ & $19.3 \pm 0.44$ & $18.3 \pm 0.63$ & $21.9 \pm 0.44$ & NA & $21.8 \pm 0.63$ & $22.9 \pm 0.25$ \\
\hline $\begin{array}{l}{[\mathrm{Fe}} \\
\mathrm{Cu}_{2}(\mathrm{Cephradine})_{2} \\
\left.\mathrm{Cl}_{5} \mathrm{H}_{2} \mathrm{O}\right] 2 \mathrm{HCl} \\
.3 \mathrm{H}_{2} \mathrm{O}\end{array}$ & $13.6 \pm 0.44$ & $11.4 \pm 0.25$ & $15.2 \pm 0.58$ & $16.2 \pm 0.44$ & $17.2 \pm 0.17$ & NA & $12.4 \pm 0.63$ & $17.1 \pm 0.25$ \\
\hline
\end{tabular}

Continued Table 2 
Doaa.A.Ghareeb et al.

\begin{tabular}{|c|c|c|c|c|c|c|c|c|}
\hline $\begin{array}{l}{[\mathrm{Fe} \mathrm{Co}} \\
\text { (Cephradine })_{2} \mathrm{Cl}_{3} \\
\left.\mathrm{H}_{2} \mathrm{O}\right] 2 \mathrm{HCl} .3 \mathrm{H}_{2} \mathrm{O}\end{array}$ & $24.8 \pm 0.63$ & $19.3 \pm 0.19$ & $19.3 \pm 0.44$ & $25.0 \pm 0.58$ & $20.6 \pm 0.44$ & NA & $19.3 \pm 0.37$ & $23.8 \pm 0.25$ \\
\hline $\begin{array}{l}{[\mathrm{Fe}} \\
\mathrm{Ni}(\mathrm{Cephradine}) \\
\left.\mathrm{Cl}_{4}\left(\mathrm{H}_{2} \mathrm{O}\right)_{2}\right] \\
\mathrm{HCl} .4 \mathrm{H}_{2} \mathrm{O} \\
\end{array}$ & $20.6 \pm 0.58$ & $17.4 \pm 0.19$ & $16.3 \pm 0.44$ & $22.2 \pm 0.58$ & $21.6 \pm 0.58$ & NA & $18.1 \pm 0.25$ & $20.7 \pm 0.44$ \\
\hline $\begin{array}{l}\text { Cefepime } \\
\text { standard }\end{array}$ & $20.3 \pm 0.19$ & $22.3 \pm 0.44$ & $20.6 \pm 0.58$ & $18.9 \pm 0.37$ & $22.6 \pm 0.19$ & $18.2 \pm 0.44$ & $22.4 \pm 0.25$ & $23.6 \pm 0.19$ \\
\hline $\begin{array}{l}{\left[\mathrm{Cr}_{2}(\text { Cefepime })\right.} \\
\left.(\mathrm{OH})_{4}\left(\mathrm{H}_{2} \mathrm{O}\right)_{4}\right] \\
\mathrm{OH} . \mathrm{H}_{2} \mathrm{O}\end{array}$ & NA & NA & NA & NA & NA & NA & NA & NA \\
\hline $\begin{array}{l}{\left[\mathrm{Mn}_{2}(\text { Cefepime })_{3}\right.} \\
\left.(\mathrm{OH})_{2}\left(\mathrm{H}_{2} \mathrm{O}\right)_{2}\right] \\
(\mathrm{OH})_{3}\end{array}$ & $20.3 \pm 0.44$ & $21.9 \pm 0.44$ & $17.9 \pm 0.63$ & $16.2 \pm 0.44$ & $20.3 \pm 0.44$ & NA & $20.6 \pm 0.58$ & $21.4 \pm 0.63$ \\
\hline $\begin{array}{l}{[\mathrm{Fe}} \\
\left.(\text { Cefepime })_{3}\right] \mathrm{Cl}_{3} \\
4 \mathrm{H}_{2} \mathrm{O} \\
\end{array}$ & $15.3 \pm 0.44$ & $16.4 \pm 0.58$ & NA & NA & $16.8 \pm 0.63$ & NA & NA & $17.1 \pm 0.25$ \\
\hline $\begin{array}{l}{[\mathrm{Fe}(\text { Cefepime })]} \\
\left.\mathrm{Cl}_{2}\left(\mathrm{H}_{2} \mathrm{O}\right)_{2}\right] \\
\mathrm{Cl} .3 \mathrm{H}_{2} \mathrm{O}\end{array}$ & $11.6 \pm 0.58$ & $13.4 \pm 0.63$ & $12.6 \pm 0.25$ & $10.6 \pm 0.44$ & $12.3 \pm 0.37$ & NA & NA & $13.6 \pm 0.58$ \\
\hline $\begin{array}{c}{\left[\mathrm{Co}_{2}(\text { Cefepime })\right.} \\
\left.(\mathrm{OH})_{3} \mathrm{H}_{2} \mathrm{O}\right](\mathrm{OH})\end{array}$ & $21.8 \pm 0.63$ & $22.4 \pm 0.58$ & $18.6 \pm 0.63$ & $17.4 \pm 0.63$ & $21.6 \pm 0.44$ & NA & $21.4 \pm 0.63$ & $22.3 \pm 0.63$ \\
\hline $\begin{array}{c}{[\mathrm{Ni} \text { (Cefepime) } \mathrm{Cl}} \\
\left.\mathrm{H}_{2} \mathrm{O}\right] \mathrm{Cl} .5 \mathrm{H}_{2} \mathrm{O} \\
\end{array}$ & $9.3 \pm 0.44$ & $11.2 \pm 0.58$ & NA & NA & $11.3 \pm 0.37$ & NA & NA & $12.4 \pm 0.44$ \\
\hline $\begin{array}{l}{\left[\mathrm{Ni}(\text { Cefepime })_{2}\right]} \\
\mathrm{Cl}_{2} \cdot 6 \mathrm{H}_{2} \mathrm{O}\end{array}$ & $23.8 \pm 0.58$ & $24.8 \pm 0.58$ & $23.8 \pm 0.44$ & $20.9 \pm 0.37$ & $23.8 \pm 0.17$ & $20.9 \pm 0.44$ & $24.8 \pm 0.18$ & $25.2 \pm 0.63$ \\
\hline $\begin{array}{l}{\left[\mathrm{Cu}(\text { Cefepime })_{3}\right]} \\
\mathrm{Cl}_{2} \cdot \mathrm{OH}\end{array}$ & $18.9 \pm 0.63$ & $20.3 \pm 0.44$ & $16.8 \pm 0.44$ & $15.3 \pm 0.17$ & $20.3 \pm 0.58$ & NA & $19.9 \pm 0.63$ & $20.5 \pm 0.58$ \\
\hline $\begin{array}{l}{\left[\mathrm{Cu}_{4}(\text { Cefepime })\right.} \\
\left.\mathrm{Cl}_{5} \mathrm{H}_{2} \mathrm{O}\right] \mathrm{Cl} . \mathrm{H}_{2} \mathrm{O}\end{array}$ & $21.8 \pm 0.58$ & $22.3 \pm 0.44$ & $23.0 \pm 0.58$ & $20.0 \pm 0.17$ & $22.2 \pm 0.44$ & $19.3 \pm 0.17$ & $23.1 \pm 0.63$ & $23.9 \pm 0.17$ \\
\hline $\begin{array}{l}\text { [Zn(Cefepime) } \mathrm{Cl} \\
\left.\mathrm{H}_{2} \mathrm{O}\right] .5 \mathrm{H}_{2} \mathrm{O}\end{array}$ & $10.9 \pm 0.63$ & $12.3 \pm 0.44$ & $\mathrm{NA}$ & NA & $13.2 \pm 0.58$ & NA & NA & $13.9 \pm 0.58$ \\
\hline $\begin{array}{c}\text { [Cd (Cefepime) } \\
\left.\mathrm{OH} \mathrm{H}_{2} \mathrm{O}\right] \mathrm{OH} \\
\end{array}$ & $17.8 \pm 0.44$ & $20.0 \pm 0.44$ & $15.6 \pm 0.58$ & $15.0 \pm 0.63$ & $19.8 \pm 0.58$ & NA & $19.8 \pm 0.44$ & $20.0 \pm 0.63$ \\
\hline $\begin{array}{l}{\left[\mathrm{Hg}(\text { Cefepime })_{2}\right]} \\
\mathrm{Cl}_{2} \cdot 6 \mathrm{H}_{2} \mathrm{O}\end{array}$ & $16.9 \pm 0.58$ & $18.2 \pm 0.63$ & NA & NA & $18.7 \pm 0.44$ & NA & NA & $20.3 \pm 0.58$ \\
\hline $\begin{array}{l}{[\mathrm{Fe} \mathrm{Cu} \text { (Cefepime) }} \\
\mathrm{Cl}_{4} \\
\left.\left(\mathrm{H}_{2} \mathrm{O}\right)_{2}\right] \mathrm{Cl} .6 \mathrm{H}_{2} \mathrm{O}\end{array}$ & $22.6 \pm 0.58$ & $23.2 \pm 0.25$ & $22.4 \pm 0.37$ & $19.6 \pm 0.17$ & $22.9 \pm 0.44$ & $20.3 \pm 0.17$ & $23.4 \pm 0.58$ & $24.8 \pm 0.17$ \\
\hline $\begin{array}{l}\text { [Fe Ni(Cefepime })_{3} \\
\left.\mathrm{Cl}_{2}\right] \mathrm{Cl}_{3} \cdot 2 \mathrm{H}_{2} \mathrm{O}\end{array}$ & $10.2 \pm 0.58$ & $11.0 \pm 0.44$ & $10.9 \pm 0.58$ & NA & $10.2 \pm 0.44$ & NA & NA & $11.3 \pm 0.58$ \\
\hline $\begin{array}{l}{\left[\mathrm{Co} \mathrm{Cu}_{3}\right.} \\
(\mathrm{Cefepime}) \mathrm{Cl}_{7} \\
\left.\mathrm{H}_{2} \mathrm{O}\right] \mathrm{Cl} .3 \mathrm{H}_{2} \mathrm{O}\end{array}$ & $10.6 \pm 0.63$ & $12.3 \pm 0.58$ & $10.9 \pm 0.25$ & $9.8 \pm 0.44$ & $11.4 \pm 0.37$ & NA & NA & $11.8 \pm 0.58$ \\
\hline
\end{tabular}

The data are expressed in the form of mean $\pm S D, N A$ : No activity

Table3. MIC $(\mu \mathrm{g} / \mathrm{ml})$ for antibacterial activity of Metallocephradines andMetallocefepimes

\begin{tabular}{|l|l|l|l|l|l|l|l|l|}
\hline Compounds & S.pyogenes & $\begin{array}{l}\text { K.pneumo } \\
\text { niae }\end{array}$ & $\begin{array}{l}\text { P.mirabil } \\
\text { is }\end{array}$ & $\begin{array}{l}\text { E.fecal } \\
\text { is }\end{array}$ & $\begin{array}{l}\text { S.pneum } \\
\text { oniae }\end{array}$ & $\begin{array}{l}\text { P.aerug } \\
\text { inosa }\end{array}$ & E.coli & $\begin{array}{l}\text { S.aure } \\
\text { us }\end{array}$ \\
\hline Cephradine standard & 1.95 & 62.5 & 62.5 & 7.81 & 3.9 & NA & 31.25 & 3.9 \\
\hline $\begin{array}{l}{\left[\mathrm{Cr}_{2}(\text { Cephradine })_{3}\right.} \\
\left.(\mathrm{OH})_{3} \mathrm{H}_{2} \mathrm{O}\right] 3 \mathrm{H}_{2} \mathrm{O}\end{array}$ & 7.81 & 1.95 & 15.63 & 31.25 & 1.95 & NA & 1.95 & 0.98 \\
\hline $\begin{array}{l}{[\mathrm{Mn}(\mathrm{Cephradine}) \mathrm{Cl}} \\
\left.\left(\mathrm{H}_{2} \mathrm{O}\right)_{3}\right] \mathrm{HCl} .2 \mathrm{H}_{2} \mathrm{O}\end{array}$ & 500 & 500 & NA & NA & 125 & NA & NA & 14.6 \\
\hline $\begin{array}{l}{\left[\mathrm{Fe}_{2}(\mathrm{Cephradine}) \mathrm{Cl}_{5}\right.} \\
\left.3 \mathrm{H}_{2} \mathrm{O}\right] \mathrm{H}_{2} \mathrm{O}\end{array}$ & 0.98 & 0.24 & 1.95 & 7.81 & 0.98 & NA & 0.24 & 0.49 \\
\hline $\begin{array}{l}{\left[\mathrm{Co}(\mathrm{Cephradine})_{3}\right]} \\
2 \mathrm{HCl} \mathrm{H}_{2} \mathrm{O}\end{array}$ & 125 & 125 & NA & NA & 62.5 & NA & NA & 31.25 \\
\hline
\end{tabular}


In Vitro Biological Screening for Antimicrobial, DNA Cleavage Anti-Diabetic, Antioxidant, AntiInflammatory and Antihaemolytic of Some Metallocephalosporins

\begin{tabular}{|c|c|c|c|c|c|c|c|c|}
\hline $\begin{array}{l}\text { [Ni (Cephradine) } \mathrm{Cl} \\
\left.\mathrm{H}_{2} \mathrm{O}\right] \mathrm{HCl} .3 \mathrm{H}_{2} \mathrm{O}\end{array}$ & 0.24 & 0.24 & 3.9 & 3.9 & 0.24 & NA & 0.12 & 0.24 \\
\hline $\begin{array}{l}{\left[\mathrm{Ni}(\text { Cephradine })_{2}\right]} \\
2 \mathrm{HCl} .\end{array}$ & 0.49 & 15.63 & 15.63 & 0.12 & 0.24 & 3.9 & 7.81 & 0.98 \\
\hline $\begin{array}{l}{\left[\mathrm{Cu}(\text { Cephradine })_{2}\right]} \\
2 \mathrm{HCl} .6 \mathrm{H}_{2} \mathrm{O}\end{array}$ & 0.98 & 0.98 & 3.9 & 15.63 & 1.95 & NA & 0.98 & 0.98 \\
\hline $\begin{array}{l}{\left[\mathrm{Cu}_{3}(\text { Cephradine }) \mathrm{Cl}_{5}\right.} \\
\left.\mathrm{H}_{2} \mathrm{O}\right] \mathrm{HCl}\end{array}$ & 0.98 & 7.81 & 31.25 & 0.24 & 0.49 & $\mathrm{NA}$ & 15.63 & 0.98 \\
\hline $\begin{array}{l}{\left[\mathrm{Zn}_{2}(\text { Cephradine }) \mathrm{Cl}_{3}\right.} \\
\left.\mathrm{H}_{2} \mathrm{O}\right] \mathrm{HCl} \cdot \mathrm{H}_{2} \mathrm{O}\end{array}$ & 0.12 & 0.06 & 1.95 & 1.95 & 0.12 & 1.95 & 0.06 & 0.12 \\
\hline $\begin{array}{l}{\left[\mathrm{Cd}_{2}(\text { Cephradine })(\mathrm{OH})_{2}\right.} \\
\left.\mathrm{Cl} \mathrm{H}_{2} \mathrm{O}\right] \mathrm{HCl} .3 \mathrm{H}_{2} \mathrm{O}\end{array}$ & 0.49 & 0.12 & 0.98 & 3.9 & 0.24 & 3.9 & 0.24 & 0.24 \\
\hline $\begin{array}{l}{\left[\mathrm{Hg}(\text { Cephradine })_{3}\right]} \\
2 \mathrm{HCl} .6 \mathrm{H}_{2} \mathrm{O}\end{array}$ & 1.95 & 62.5 & 62.5 & 7.81 & 3.9 & NA & 31.25 & 3.9 \\
\hline $\begin{array}{l}{\left[\mathrm{Fe} \mathrm{Co}(\text { Cephradine })_{2} \mathrm{Cl}_{3}\right.} \\
\left.\mathrm{H}_{2} \mathrm{O}\right] 2 \mathrm{HCl} .3 \mathrm{H}_{2} \mathrm{O}\end{array}$ & 26 & 0.24 & 7.81 & 7.81 & 0.12 & 3.9 & NA & 7.81 \\
\hline $\begin{array}{l}\text { [Fe Ni(Cephradine) } \mathrm{Cl}_{4} \\
\left.\left(\mathrm{H}_{2} \mathrm{O}\right)_{2}\right] \mathrm{HCl} .4 \mathrm{H}_{2} \mathrm{O}\end{array}$ & 3.9 & 31.25 & 62.5 & 0.98 & 1.95 & NA & 15.63 & 1.95 \\
\hline Cefepime standard & 3.9 & 0.98 & 1.95 & 7.81 & 0.98 & 15.63 & 0.98 & 0.49 \\
\hline $\begin{array}{l}{\left[\mathrm{Mn}_{2}\right.} \\
(\mathrm{Cefepime})_{3} \cdot(\mathrm{OH})_{2 .}\left(\mathrm{H}_{2} \mathrm{O}\right. \\
\left.)_{2}\right](\mathrm{OH})_{3}\end{array}$ & 1.95 & 0.49 & 7.81 & 31.25 & 1.95 & NA & 1.95 & 0.98 \\
\hline $\begin{array}{l}{\left[\mathrm{Fe}(\text { Cefepime })_{3}\right]} \\
\mathrm{Cl}_{3} .4 \mathrm{H}_{2} \mathrm{O}\end{array}$ & 62.5 & 31.25 & NA & NA & 31.25 & NA & NA & 15.63 \\
\hline $\begin{array}{l}{\left[\mathrm{Co}_{2} \text { (Cefepime) }\right.} \\
\left.\mathrm{H}_{2} \mathrm{O}\right] \mathrm{OH}\end{array}$ & 0.49 & 0.49 & 3.9 & 15.63 & 0.49 & NA & 0.98 & 0.49 \\
\hline $\begin{array}{l}{\left[\mathrm{Ni}(\text { Cefepime })_{2}\right]} \\
\mathrm{Cl}_{2} \cdot 6 \mathrm{H}_{2} \mathrm{O}\end{array}$ & 0.49 & 0.24 & 0.49 & 1.95 & 0.24 & 1.95 & 0.12 & 0.12 \\
\hline $\begin{array}{l}{\left[\mathrm{Cu}(\text { Cefepime })_{3}\right]} \\
\mathrm{Cl}_{2} . \mathrm{OH}\end{array}$ & 3.9 & 1.95 & 15.63 & 62.5 & 3.9 & NA & 1.95 & 0.98 \\
\hline $\begin{array}{l}{[\mathrm{Zn}(\text { Cefepime }) \mathrm{Cl}} \\
\left.\mathrm{H}_{2} \mathrm{O}\right] .5 \mathrm{H}_{2} \mathrm{O}\end{array}$ & 500 & 500 & NA & NA & 500 & NA & NA & 125 \\
\hline $\begin{array}{l}{[\mathrm{Cd}(\text { Cefepime }) \mathrm{OH}} \\
\left.\mathrm{H}_{2} \mathrm{O}\right] \mathrm{OH}\end{array}$ & 7.81 & 1.95 & 62.5 & 62.5 & 1.95 & NA & 3.9 & 1.95 \\
\hline $\begin{array}{l}{\left[\mathrm{Hg}(\text { Cefepime })_{2}\right] \mathrm{Cl}_{2} \text {. }} \\
6 \mathrm{H}_{2} \mathrm{O}\end{array}$ & 15.63 & 7.81 & NA & NA & 3.9 & NA & NA & 1.95 \\
\hline $\begin{array}{l}\text { [Fe Cu(Cefepime) } \mathrm{Cl}_{4} \\
\left.\left(\mathrm{H}_{2} \mathrm{O}\right)_{2}\right] \mathrm{Cl} \cdot 6 \mathrm{H}_{2} \mathrm{O}\end{array}$ & 0.98 & 0.98 & 0.98 & 3.9 & 0.98 & 3.9 & 0.49 & 0.24 \\
\hline
\end{tabular}

Table4. Antifungal activity of Metallocephradines and Metallocefepimes

\begin{tabular}{|c|c|c|c|c|c|c|c|c|}
\hline Compounds & A.niger & A.flavus & $\begin{array}{l}\text { S.racemos } \\
\text { um }\end{array}$ & C.albicans & C.glabrata & $\begin{array}{l}\text { F.oxyspor } \\
\text { um }\end{array}$ & R.solani & A.solani \\
\hline $\begin{array}{l}\text { Amphotericin B } \\
\text { standard }\end{array}$ & $20.4 \pm 0.44$ & $17.3 \pm 0.25$ & $20.7 \pm 0.25$ & $22.0 \pm 0.21$ & $21.7 \pm 0.58$ & $24.6 \pm 0.26$ & $26.7 \pm 0.37$ & $24.3 \pm 0.44$ \\
\hline Cephradine & $11.6 \pm 0.44$ & $10.7 \pm 0.25$ & $13.2 \pm 0.58$ & NA & $11.4 \pm 0.37$ & $12.2 \pm 0.44$ & $\mathrm{NA}$ & $9.4 \pm 0.25$ \\
\hline $\begin{array}{l}{\left[\mathrm{Cr}_{2} \text { (Cephradine }\right)_{3}} \\
\left.(\mathrm{OH})_{3} \mathrm{H}_{2} \mathrm{O}\right] 3 \mathrm{H}_{2} \mathrm{O}\end{array}$ & $18.3 \pm 0.44$ & $19.9 \pm 0.58$ & $18.0 \pm 0.19$ & NA & $16.3 \pm 0.44$ & $21.0 \pm 0.37$ & $\mathrm{NA}$ & $13.0 \pm 0.44$ \\
\hline \begin{tabular}{|l|}
$\mathrm{Mn}(\mathrm{Cephradine})$ \\
$\left.\mathrm{Cl}\left(\mathrm{H}_{2} \mathrm{O}\right)_{3}\right] \mathrm{HCl} .2 \mathrm{H}_{2}$ \\
$\mathrm{O}$
\end{tabular} & $13.6 \pm 0.44$ & $11.0 \pm 0.37$ & $13.4 \pm 0.58$ & NA & $12.4 \pm 0.58$ & $16.3 \mathrm{v} 0.37$ & $\mathrm{NA}$ & $10.4 \pm 0.25$ \\
\hline \begin{tabular}{|l|}
{$\left[\mathrm{Fe}_{2}(\right.$ Cephradine $)$} \\
$\left.\mathrm{Cl}_{5}\left(\mathrm{H}_{2} \mathrm{O}\right)_{3}\right] \mathrm{H}_{2} \mathrm{O}$
\end{tabular} & $19.3 \pm 0.44$ & $20.0 \pm 0.58$ & $18.2 \pm 0.19$ & NA & $16.5 \pm 0.44$ & $21.4 \pm 0.37$ & NA & $13.7 \pm 0.44$ \\
\hline $\begin{array}{l}{\left[\mathrm{Co}(\text { Cephradine })_{3}\right]} \\
2 \mathrm{HCl} \cdot \mathrm{H}_{2} \mathrm{O}\end{array}$ & $12.3 \pm 0.37$ & $9.3 \pm 0.44$ & $10.5 \pm 0.58$ & NA & $11.6 \pm 0.44$ & $12.4 \pm 0.25$ & $\mathrm{NA}$ & $10.3 \pm 0.44$ \\
\hline \begin{tabular}{|l|}
$\mathrm{Ni}$ (Cephradine) $\mathrm{Cl}$ \\
$\left.\mathrm{H}_{2} \mathrm{O}\right] \mathrm{HCl} .3 \mathrm{H}_{2} \mathrm{O}$
\end{tabular} & $18.2 \pm 0.44$ & $19.3 \pm 0.58$ & $17.8 \pm 0.19$ & NA & $16.3 \pm 0.44$ & $20.9 \pm 0.37$ & $\mathrm{NA}$ & $12.6 \pm 0.44$ \\
\hline $\begin{array}{l}{[\mathrm{Ni}} \\
\left.(\text { Cephradine })_{2}\right] 2 \mathrm{HCl}\end{array}$ & $16.8 \pm 0.44$ & $17.2 \pm 0.63$ & $18.3 \pm 0.44$ & NA & $15.4 \pm 0.44$ & $22.3 \pm 0.37$ & NAs & NA \\
\hline
\end{tabular}


Doaa.A.Ghareeb et al.

\begin{tabular}{|c|c|c|c|c|c|c|c|c|}
\hline $\begin{array}{l}{\left[\mathrm{Cu} \quad(\text { Cephradine })_{2}\right.} \\
2 \mathrm{HCl} .6 \mathrm{H}_{2} \mathrm{O}\end{array}$ & $13.3 \pm 0.25$ & $12.4 \pm 0.44$ & $13.6 \pm 0.44$ & NA & $\mid 13.7 \pm 0.37$ & $15.0 \pm 0.37$ & $\mathrm{NA}$ & $\mid 10.0 \pm 0.44$ \\
\hline \begin{tabular}{|l|}
{$\left[\mathrm{Cu}_{3}(\right.$ Cephradine $)$} \\
$\left.\mathrm{Cl}_{5} \mathrm{H}_{2} \mathrm{O}\right] \mathrm{HCl}$
\end{tabular} & $15.6 \pm 0.25$ & $16.9 \pm 0.37$ & $17.2 \pm 0.58$ & $\mathrm{NA}$ & $13.9 \pm 0.63$ & $21.3 \pm 0.44$ & NA & NA \\
\hline \begin{tabular}{|l}
{$\left[\mathrm{Zn}_{2}\right.$ (Cephradine) } \\
$\left.\mathrm{Cl}_{3} \mathrm{H}_{2} \mathrm{O}\right] \mathrm{HCl} \cdot \mathrm{H}_{2} \mathrm{O}$
\end{tabular} & 13.40 .58 & $12.7 \pm 0.37$ & $14.3 \pm 0.58$ & $\mathrm{NA}$ & $13.8 \pm 0.44$ & $17.2 \pm 0.25$ & NA & $10.7 \pm 0.25$ \\
\hline $\begin{array}{l}\mathrm{Cd}_{2}(\text { Cephradine }) \\
\left.(\mathrm{OH})_{2} \mathrm{Cl} \mathrm{H} \mathrm{H}_{2} \mathrm{O}\right] \\
\mathrm{HCl} .3 \mathrm{H}_{2} \mathrm{O} \\
\end{array}$ & $15.7 \pm 0.37$ & $16.1 \pm 0.27$ & $13.3 \pm 0.44$ & $\mathrm{NA}$ & $15.4 \pm 0.44$ & $18.3 \pm 0.37$ & $\mathrm{NA}$ & $11.1 \pm 0.25$ \\
\hline $\begin{array}{l}{\left[\mathrm{Hg}(\text { Cephradine })_{3}\right]} \\
2 \mathrm{HCl} .6 \mathrm{H}_{2} \mathrm{O}\end{array}$ & $22.6 \pm 0.16$ & $21.9 \pm 0.37$ & $19.9 \pm 0.28$ & $\mathrm{NA}$ & $18.7 \pm 0.35$ & $23.4 \pm 0.19$ & NA & $15.3 \pm 0.12$ \\
\hline $\begin{array}{l}{[\mathrm{Fe}} \\
\mathrm{Cu}_{2}(\text { Cephradine })_{2} \mathrm{Cl} \\
\left.{ }_{5} \mathrm{H}_{2} \mathrm{O}\right] 2 \mathrm{HCl} .3 \mathrm{H}_{2} \mathrm{O}\end{array}$ & $12.3 \pm 0.63$ & $12.6 \pm 0.25$ & $12.6 \pm 0.58$ & $\mathrm{NA}$ & $11.6 \pm 0.58$ & $15.6 \pm 0.37$ & NA & NA \\
\hline $\begin{array}{l}{[\mathrm{Fe}} \\
\mathrm{Co}(\text { Cephradine })_{2} \\
\left.\mathrm{Cl}_{3} \mathrm{H}_{2} \mathrm{O}\right] \\
2 \mathrm{HCl}_{3} 3 \mathrm{H}_{2} \mathrm{O}\end{array}$ & $17.2 \pm 0.37$ & $17.9 \pm 0.37$ & $19.3 \pm 0.44$ & $\mathrm{NA}$ & $16.1 \pm 0.58$ & $23.9 \pm 0.63$ & NA & NA \\
\hline $\begin{array}{l}{[\mathrm{Fe} \text { Ni(Cephradine) }} \\
\left.\mathrm{Cl}_{4}\left(\mathrm{H}_{2} \mathrm{O}\right)_{2}\right] \\
\mathrm{HCl} .4 \mathrm{H}_{2} \mathrm{O}\end{array}$ & $16.9 \pm 0.25$ & $17.6 \pm 0.58$ & $18.9 \pm 0.25$ & $\mathrm{NA}$ & $15.2 \pm 0.63$ & $23.4 \pm 0.44$ & $\mathrm{NA}$ & NA \\
\hline Cefepime & $12.7 \pm 0.37$ & $13.1 \pm 0.44$ & $14.0 \pm 0.19$ & $\mathrm{NA}$ & $11.7 \pm 0.58$ & $12.0 \pm 0.58$ & NA & $9.8 \pm 0.44$ \\
\hline $\begin{array}{l}{\left[\mathrm{Cr}_{2}(\mathrm{Cefepime})\right.} \\
\left.(\mathrm{OH})_{4}\left(\mathrm{H}_{2} \mathrm{O}\right)_{4}\right] \\
\mathrm{OH} . \mathrm{H}_{2} \mathrm{O}\end{array}$ & $19.9 \pm 0.58$ & $20.6 \pm 0.44$ & $17.1 \pm 0.25$ & NA & $15.3 \pm 0.44$ & $21.0 \pm 0.25$ & NA & $12.8 \pm 0.44$ \\
\hline $\begin{array}{l}{\left[\mathrm{Mn}_{2}(\text { Cefepime })_{3}\right.} \\
\left.(\mathrm{OH})_{2}\left(\mathrm{H}_{2} \mathrm{O}\right)_{2}\right] \\
(\mathrm{OH})_{3}\end{array}$ & $14.9 \pm 0.58$ & $16.4 \pm 0.19$ & $14.7 \pm 0.25$ & $\mathrm{NA}$ & $16.2 \pm 0.44$ & $15.3 \pm 0.44$ & $\mathrm{NA}$ & $12.8 \pm 0.25$ \\
\hline $\begin{array}{l}{\left[\begin{array}{ll}\mathrm{Fe} & (\text { Cefepime })_{3}\end{array}\right]} \\
\mathrm{Cl}_{3} \cdot 4 \mathrm{H}_{2} \mathrm{O}\end{array}$ & $9.3 \pm 0.44$ & $8.3 \pm 0.19$ & $13.3 \pm 0.37$ & $\mathrm{NA}$ & $9.4 \pm 0.37$ & $12.1 \pm 0.19$ & $\mathrm{NA}$ & $8.3 \pm 0.37$ \\
\hline $\begin{array}{l}{[\mathrm{Fe} \text { (Cefepime) }]} \\
\left.\mathrm{Cl}_{2}\left(\mathrm{H}_{2} \mathrm{O}\right)_{2}\right] \\
\mathrm{Cl} .3 \mathrm{H}_{2} \mathrm{O}\end{array}$ & $10.2 \pm 0.37$ & $9.3 \pm 0.44$ & $11.3 \pm 0.58$ & $\mathrm{NA}$ & $10.6 \pm 0.37$ & $12.3 \pm 0.44$ & $\mathrm{NA}$ & NA \\
\hline $\begin{array}{l}{\left[\mathrm{Co}_{2}(\text { Cefepime })\right.} \\
\left.(\mathrm{OH})_{3} \mathrm{H}_{2} \mathrm{O}\right](\mathrm{OH})\end{array}$ & $20.4 \pm 0.13$ & $20.9 \pm 0.44$ & $18.9 \pm 0.25$ & $\mathrm{NA}$ & $16.4 \pm 0.25$ & $22.6 \pm 0.30$ & NA & $14.6 \pm 0.14$ \\
\hline $\begin{array}{l}{[\mathrm{Ni} \text { (Cefepime) } \mathrm{Cl}} \\
\left.\mathrm{H}_{2} \mathrm{O}\right] \mathrm{Cl} .5 \mathrm{H}_{2} \mathrm{O}\end{array}$ & $\begin{array}{l}15.7 \\
0.44\end{array}$ & $+\begin{array}{l}17.4 \\
0.25\end{array}$ & $13.9 \pm 0.32$ & $\mathrm{NA}$ & $16.8 \pm 0.37$ & $\begin{array}{l}15.9 \\
0.44\end{array}$ & $\mathrm{NA}$ & $\begin{array}{l}12.6 \pm \\
0.25\end{array}$ \\
\hline $\begin{array}{l}\left.[\mathrm{Ni} \text { (Cefepime) })_{2}\right] \\
\mathrm{Cl}_{2} \cdot 6 \mathrm{H}_{2} \mathrm{O}\end{array}$ & $16.2 \pm 0.25$ & $15.3 \pm 0.44$ & $16.4 \pm 0.58$ & $\mathrm{NA}$ & $13.6 \pm 0.37$ & $20.3 \pm 0.58$ & NA & NA \\
\hline $\begin{array}{l}{\left[\mathrm{Cu}(\text { Cefepime })_{3}\right]} \\
\mathrm{Cl}_{2} \cdot \mathrm{OH}\end{array}$ & $18.9 \pm 0.22$ & $20.2 \pm 0.25$ & $16.8 \pm 0.44$ & $\mathrm{NA}$ & $19.2 \pm 0.17$ & $20.8 \pm 0.29$ & NA & $13.5 \pm 0.42$ \\
\hline 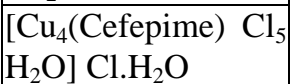 & $14.3 \pm 0.37$ & $12.6 \pm 0.63$ & $15.6 \pm 0.44$ & $\mathrm{NA}$ & $12.9 \pm 0.58$ & $15.6 \pm 0.44$ & $\mathrm{NA}$ & $\mathrm{NA}$ \\
\hline $\begin{array}{l}{[\mathrm{Zn}(\text { Cefepime }) \mathrm{Cl}} \\
\left.\mathrm{H}_{2} \mathrm{O}\right] \cdot 5 \mathrm{H}_{2} \mathrm{O}\end{array}$ & $\begin{array}{l}14.2 \\
0.44\end{array}$ & $\begin{array}{l}15.8 \\
0.58\end{array}$ & $=12.4 \pm 0.44$ & NA & $15.8 \pm 0.44$ & $\begin{array}{l}14.2 \\
0.37\end{array}$ & $\mathrm{NA}$ & $\begin{array}{l}12.0 \pm \\
0.58\end{array}$ \\
\hline $\begin{array}{l}{[\mathrm{Cd} \text { (Cefepime) } \mathrm{OH}} \\
\left.\mathrm{H}_{2} \mathrm{O}\right] \mathrm{OH}\end{array}$ & $\begin{array}{l}17.9 \\
0.44\end{array}$ & $+\begin{array}{l}19.9 \\
0.44\end{array}$ & $16.8 \pm 0.44$ & $\mathrm{NA}$ & $18.2 \pm 0.44$ & $20.0 \pm 0.58$ & $\mathrm{NA}$ & $13.0 \pm 0.25$ \\
\hline $\begin{array}{l}{\left[\mathrm{Hg}(\text { Cefepime })_{2}\right]} \\
\mathrm{Cl}_{2} \cdot 6 \mathrm{H}_{2} \mathrm{O}\end{array}$ & $17.3 \pm 0.58$ & $19.4 \pm 0.44$ & $15.3 \pm 0.25$ & $\mathrm{NA}$ & $14.2 \pm 0.44$ & $19.4 \pm 0.25$ & $\mathrm{NA}$ & $12.8 \pm 0.44$ \\
\hline $\begin{array}{ll}{[\mathrm{Fe}} & \mathrm{Cu}(\text { Cefepime }) \\
\mathrm{Cl}_{4} & \left.\left(\mathrm{H}_{2} \mathrm{O}\right)_{2}\right] \mathrm{Cl} \cdot 6 \mathrm{H}_{2} \mathrm{O}\end{array}$ & $17.9 \pm 0.44$ & $16.8 \pm 0.58$ & $18.6 \pm 0.63$ & $\mathrm{NA}$ & $16.2 \pm 0.44$ & $20.9 \pm 0.37$ & NA & NA \\
\hline \begin{tabular}{|l|}
{$[\mathrm{Fe}$} \\
$\left.\mathrm{Ni}(\text { Cefepime })_{3} \mathrm{Cl}_{2}\right]$ \\
$\mathrm{Cl}_{3} \cdot 2 \mathrm{H}_{2} \mathrm{O}$
\end{tabular} & $12.3 \pm 0.58$ & $10.6 \pm 0.37$ & $14.2 \pm 0.44$ & $\mathrm{NA}$ & $11.6 \pm 0.25$ & $13.7 \pm 0.37$ & $\mathrm{NA}$ & NA \\
\hline
\end{tabular}

Table5. MICs for antifungal activity of Metallocephradines and Metallocefepimes

\begin{tabular}{|c|c|c|c|c|c|c|c|c|}
\hline Compounds & A.nige & A.flavus & $\begin{array}{l}\text { S.racemos } \\
\text { um }\end{array}$ & $\begin{array}{l}\text { C.albica } \\
\text { ns }\end{array}$ & C.glabrata & F.oxysporum & $\begin{array}{l}\text { R.sol } \\
\text { ani }\end{array}$ & A.solani \\
\hline $\begin{array}{l}\text { Amphotericin B } \\
\text { standard }\end{array}$ & 0.49 & 3.9 & 0.49 & 0.12 & 0.24 & 0.03 & $\begin{array}{l}0.00 \\
7\end{array}$ & 0.03 \\
\hline
\end{tabular}

Continued Table 5 
In Vitro Biological Screening for Antimicrobial, DNA Cleavage Anti-Diabetic, Antioxidant, AntiInflammatory and Antihaemolytic of Some Metallocephalosporins

\begin{tabular}{|c|c|c|c|c|c|c|c|c|}
\hline Cephradine & 250 & 250 & 62.5 & NA & 250 & 250 & NA & 500 \\
\hline $\begin{array}{l}{\left[\mathrm{Cr}_{2}(\text { Cephradine })_{3}\right.} \\
\left.(\mathrm{OH})_{3} \mathrm{H}_{2} \mathrm{O}\right] 3 \mathrm{H}_{2} \mathrm{O} \\
\end{array}$ & 3.9 & 0.98 & 1.95 & NA & 7.8 & 0.24 & NA & 62.5 \\
\hline $\begin{array}{l}{\left[\mathrm{Fe}_{2}(\mathrm{Cephradine}) \mathrm{Cl}_{5}\right.} \\
\left.\left(\mathrm{H}_{2} \mathrm{O}\right)_{3}\right] \mathrm{H}_{2} \mathrm{O}\end{array}$ & 7.8 & 1.95 & 7.8 & NA & 3.9 & 7.8 & NA & 62.5 \\
\hline $\begin{array}{l}\mathrm{Ni} \text { (Cephradine) } \mathrm{Cl} \\
\left.\mathrm{H}_{2} \mathrm{O}\right] \mathrm{HCl} .3 \mathrm{H}_{2} \mathrm{O}\end{array}$ & 3.9 & 0.98 & 3.9 & NA & 7.8 & 0.49 & NA & 125 \\
\hline $\begin{array}{l}{\left[\mathrm{Ni}(\text { Cephradine })_{2}\right]} \\
2 \mathrm{HCl} .\end{array}$ & 31.25 & 15.63 & 15.63 & NA & 62.5 & 0.24 & NA & NA \\
\hline $\begin{array}{l}{\left[\mathrm{Cu}_{4}(\text { Cephradine }) \mathrm{Cl}_{5}\right.} \\
\left.\mathrm{H}_{2} \mathrm{O}\right] \mathrm{HCl}\end{array}$ & 125 & 32.25 & 31.25 & NA & 500 & 3.9 & NA & NA \\
\hline $\begin{array}{l}{\left[\mathrm{Hg}(\text { Cephradine })_{3}\right]} \\
2 \mathrm{HCl} .6 \mathrm{H}_{2} \mathrm{O}\end{array}$ & 0.12 & 0.24 & 0.98 & NA & 1.95 & 0.06 & NA & 15.63 \\
\hline $\begin{array}{c}\mathrm{Fe} \mathrm{Co}(\mathrm{Cephradine})_{2} \\
\left.\mathrm{Cl}_{3} \mathrm{H}_{2} \mathrm{O}\right] 2 \mathrm{HCl} .3 \mathrm{H}_{2} \mathrm{O}\end{array}$ & 31.25 & 15.63 & 7.81 & NA & 62.5 & 0.24 & NA & NA \\
\hline $\begin{array}{l}{\left[\mathrm{Fe} \mathrm{Ni}(\text { Cephradine }) \mathrm{Cl}_{4}\right.} \\
\left.\left(\mathrm{H}_{2} \mathrm{O}\right)_{2}\right] \mathrm{HCl} .4 \mathrm{H}_{2} \mathrm{O}\end{array}$ & 31.25 & 15.63 & 7.81 & NA & 125 & 0.49 & NA & NA \\
\hline Cefepime & 125 & 62.5 & 32.25 & NA & 250 & 125 & NA & 500 \\
\hline $\begin{array}{l}{\left[\mathrm{Cr}_{2} \text { (Cefepime) }(\mathrm{OH})_{4}\right.} \\
\left.\left(\mathrm{H}_{2} \mathrm{O}\right)_{4}\right] \mathrm{OH} \cdot \mathrm{H}_{2} \mathrm{O}\end{array}$ & 0.98 & 0.49 & 3.9 & NA & 31.25 & 0.49 & NA & 62.5 \\
\hline $\begin{array}{l}{\left[\mathrm{Co}_{2}(\text { Cefepime })(\mathrm{OH})_{3}\right.} \\
\left.\mathrm{H}_{2} \mathrm{O}\right](\mathrm{OH})\end{array}$ & 0.49 & 0.49 & 1.95 & NA & 7.8 & 0.12 & NA & 31.25 \\
\hline $\begin{array}{l}{[\mathrm{Ni}} \\
\left.(\mathrm{Cefepime})_{2}\right] \cdot \mathrm{Cl}_{2} \cdot 6 \mathrm{H}_{2} \mathrm{O}\end{array}$ & 62.5 & 62.5 & 62.5 & NA & 125 & 3.9 & NA & NA \\
\hline $\begin{array}{l}{\left[\mathrm{Cu}(\text { Cefepime })_{3}\right]} \\
\mathrm{Cl}_{2} \cdot \mathrm{OH}\end{array}$ & 1.95 & 0.98 & 7.8 & NA & 1.95 & 0.49 & NA & 62.5 \\
\hline $\begin{array}{l}\text { [Cd (Cefepime) } \mathrm{OH} \\
\left.\mathrm{H}_{2} \mathrm{O}\right] \mathrm{OH}\end{array}$ & 3.9 & 1.95 & 7.8 & NA & 3.9 & 0.98 & NA & 125 \\
\hline $\begin{array}{l}\text { [Fe Cu (Cefepime) } \mathrm{Cl}_{4} \\
\left.\left(\mathrm{H}_{2} \mathrm{O}\right)_{2}\right] \mathrm{Cl} .6 \mathrm{H}_{2} \mathrm{O}\end{array}$ & 15.63 & 31.25 & 15.63 & NA & 62.5 & 1.95 & NA & NA \\
\hline
\end{tabular}

\subsection{DNA-Cleavage}

The cleavage efficiency of the complexes compared with that of the control is due to their efficient DNA-binding ability [52]. The cleavage is inhibited bythe free radical scavengers implying that hydroxyl radical or peroxy derivatives mediate the cleavage reaction. The reaction is modulated by a metalloantibiotics bound hydroxyl radical or a peroxo species generated from the co-reactant $\mathrm{H}_{2} \mathrm{O}_{2}$.In the present study, the CT-DNA gel electrophoresis experiment was conducted at $35{ }^{\circ} \mathrm{C}$ using our synthesized complexes in the presence of $\mathrm{H}_{2} \mathrm{O}_{2}$ as an oxidant.Figure 2 indicates that the presence of $\mathrm{H}_{2} \mathrm{O}_{2}$ lead to DNA fragmentation which indicated by DNA smearing in the control (lane 3). Cephradine, $\left[\mathrm{Hg}(\text { Cephradine })_{3}\right] 2 \mathrm{HCl} .6 \mathrm{H}_{2} \mathrm{O},\left[\mathrm{Cr}_{2}(\mathrm{Cephradine})_{3}(\mathrm{OH})_{3} \mathrm{H}_{2} \mathrm{O}\right] 3 \mathrm{H}_{2} \mathrm{O},\left[\mathrm{Cu}(\mathrm{Cephradine})_{2}\right]$ $2 \mathrm{HCl} .6 \mathrm{H}_{2} \mathrm{O}$, [Mn(Cephradine $\left.) \mathrm{Cl}\left(\mathrm{H}_{2} \mathrm{O}\right)_{3}\right] \mathrm{HCl} .2 \mathrm{H}_{2} \mathrm{O}$ and $\left.[\mathrm{Fe} \mathrm{Co} \text { (Cephradine })_{2} \mathrm{Cl}_{3} \mathrm{H}_{2} \mathrm{O}\right] 2 \mathrm{HCl}_{2} 3 \mathrm{H}_{2} \mathrm{O}$ prevented the adverse effect of $\mathrm{H}_{2} \mathrm{O}_{2}$ on DNA as the smearing decreased progressively, while the remaining compounds increased the DNA fragmentation as the smear and intensity were progressively increased.

Also, Figure 3 indicates that $\mathrm{H}_{2} \mathrm{O}_{2}$ fragmented DNA (lane3) where, $\left.[\mathrm{Ni} \text { (Cefepime) })_{2}\right] \cdot 2 \mathrm{Cl}_{2} \cdot 6 \mathrm{H}_{2} \mathrm{O}$ and [ $\left.\mathrm{FeCu}(\mathrm{Cefepime}) \mathrm{Cl}_{4}\left(\mathrm{H}_{2} \mathrm{O}\right)_{2}\right] \mathrm{Cl} \cdot 6 \mathrm{H}_{2} \mathrm{O}$ increased DNA fragmentation, while [Co $\mathrm{Cu}_{3}$ (Cefepime) $\mathrm{Cl}_{7}$. $\left.\mathrm{H}_{2} \mathrm{O}\right] \mathrm{Cl} .3 \mathrm{H}_{2} \mathrm{O}$ and $\left[\mathrm{Fe}\right.$ (Cefepime) $\left.\mathrm{Cl}_{2}\left(\mathrm{H}_{2} \mathrm{O}\right)_{2}\right] \mathrm{Cl} .3 \mathrm{H}_{2} \mathrm{O}$ complexes decreased DNA fragmentation, while the remaining compounds had no effect.In oxidative DNA cleavage mechanism, metal ions in the complexes react with $\mathrm{H}_{2} \mathrm{O}_{2}$ to generate the hydroxyl radical, which attacks at the $\mathrm{C} 4$ position of the sugar moiety and finally cleaves the DNA. Metal complexes react with $\mathrm{H}_{2} \mathrm{O}_{2}$ to produce hydroxyl radical, hydroxyl ion and $\mathrm{Cu}$ (II) form. The formations of hydroxyl radical by the metal complexes are further compared with other complexes with $\mathrm{H}_{2} \mathrm{O}_{2}$. Hence, some metalloantibiotics can promote redox mediated cleavage of DNA reaction on sugar ring. The presence of a smear in the gel diagram indicates the presence of radical cleavage [53-54]. 


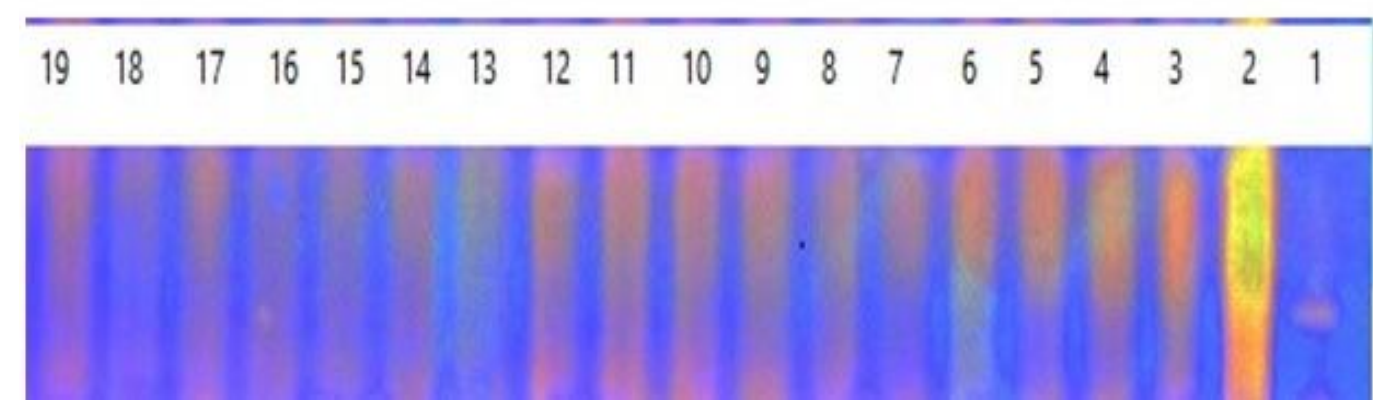

Figure2.DNA cleavage study by Metallocephradines in the presenceof $\mathrm{H}_{2} \mathrm{O}_{2}$

\begin{tabular}{|c|c|}
\hline 1-DNA Ladder & 2-Blank \\
\hline 3-Control $\mathrm{H}_{2} \mathrm{O}$ & 4- Control DMSO \\
\hline 5-Cephradine & 6- $\left[\mathrm{Hg}(\text { Cephradine })_{3}\right] 2 \mathrm{HCl} .6 \mathrm{H}_{2} \mathrm{O}$ \\
\hline 7- $\left[\mathrm{Cr}_{2}(\text { Cephradine })_{3}(\mathrm{OH})_{3} \mathrm{H}_{2} \mathrm{O}\right] 3 \mathrm{H}_{2} \mathrm{O}$ & 8- $\left[\mathrm{Cu}(\text { Cephradine })_{2}\right] 2 \mathrm{HCl} .6 \mathrm{H}_{2} \mathrm{O}$ \\
\hline 9- $\left[\mathrm{Zn}_{2}(\right.$ Cephradine $\left.) \mathrm{Cl}_{3} \mathrm{H}_{2} \mathrm{O}\right] \mathrm{HCl} \cdot \mathrm{H}_{2} \mathrm{O}$ & 10- $\left[\mathrm{Fe}_{2}(\right.$ Cephradine $\left.) \mathrm{Cl}_{5}\left(\mathrm{H}_{2} \mathrm{O}\right)_{3}\right] \mathrm{H}_{2} \mathrm{O}$ \\
\hline 11- $\left[\mathrm{Cd}_{2}(\right.$ Cephradine $\left.)(\mathrm{OH})_{2} \mathrm{Cl}_{3}\right] \mathrm{HCl} \cdot \mathrm{H}_{2} \mathrm{O}$ & 12- $\left[\mathrm{Ni}\right.$ (Cephradine) $\left.\mathrm{ClH}_{2} \mathrm{O}\right] \mathrm{HCl} .3 \mathrm{H}_{2} \mathrm{O}$ \\
\hline 13- $\left[\mathrm{Mn}(\right.$ Cephradine $\left.) \mathrm{Cl}\left(\mathrm{H}_{2} \mathrm{O}\right)_{3}\right] \mathrm{HCl} \cdot 2 \mathrm{H}_{2} \mathrm{O}$ & 14- $\left[\mathrm{Co}(\text { Cephradine })_{3}\right] 2 \mathrm{HCl} . \mathrm{H}_{2} \mathrm{O}$ \\
\hline 15- $\left[\mathrm{Cu}_{3}(\right.$ Cephradine $\left.) \mathrm{Cl}_{5} \mathrm{H}_{2} \mathrm{O}\right] \mathrm{HCl}$ & 16- $\left[\mathrm{Ni}\right.$ (Cephradine) $\left.{ }_{2} \mathrm{ClH}_{2} \mathrm{O}\right] 2 \mathrm{HCl}$. \\
\hline 17- $\left[\mathrm{Fe} \mathrm{Cu} \mathrm{Cu}_{2}(\mathrm{Cephradine})_{2} \mathrm{Cl}_{5} \mathrm{H}_{2} \mathrm{O}\right] 2 \mathrm{HCl} .3 \mathrm{H}_{2} \mathrm{O}$ & 18- $\left[\mathrm{Fe} \mathrm{Co}(\text { Cephradine })_{2} \mathrm{Cl}_{3} \mathrm{H}_{2} \mathrm{O}\right] 2 \mathrm{HCl} .3 \mathrm{H}_{2} \mathrm{O}$ \\
\hline 19- $\left[\mathrm{Fe} \mathrm{Ni}(\mathrm{Cephradine}) \mathrm{Cl}_{4}\left(\mathrm{H}_{2} \mathrm{O}\right)_{2}\right] \mathrm{HCl} .4 \mathrm{H}_{2} \mathrm{O}$ & \\
\hline
\end{tabular}

Lane

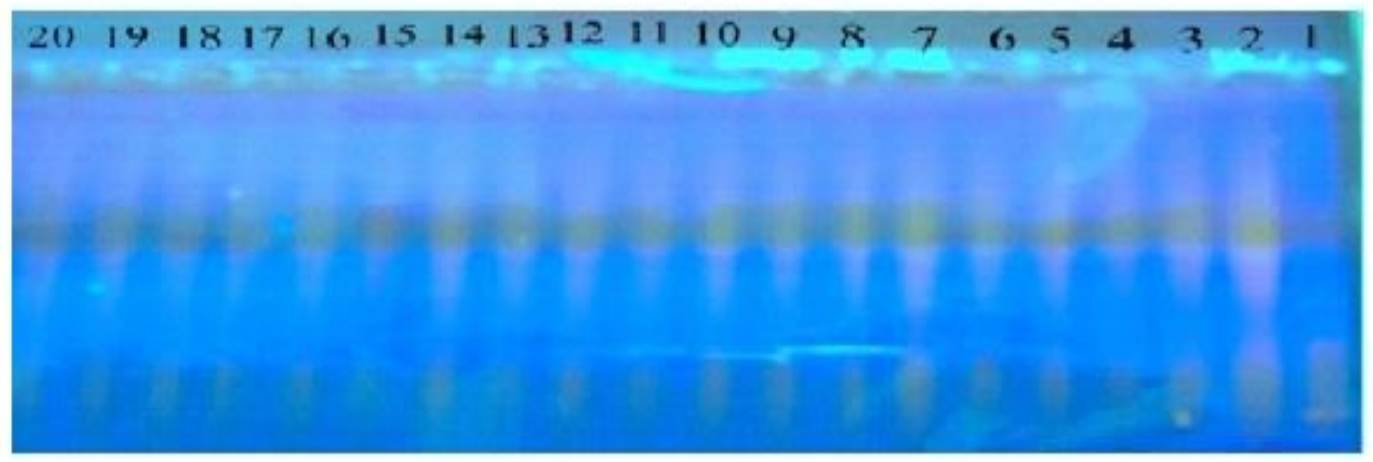

Figure3. DNA cleavage study by cefepime and its metal complexes in the presence of $\mathrm{H}_{2} \mathrm{O}_{2}$

\begin{tabular}{|c|c|}
\hline 1-DNA ladder & 2-Blank \\
\hline 3-Control $\mathrm{H}_{2} \mathrm{O}$ & 4- Control DMSO \\
\hline 5-Cefepime & 6- $\left[\mathrm{Ni}\right.$ (Cefepime) $\left.\mathrm{ClH}_{2} \mathrm{O}\right] \mathrm{Cl} .5 \mathrm{H}_{2} \mathrm{O}$ \\
\hline 7- $\left[\mathrm{Zn}(\right.$ Cefepime $\left.) \mathrm{ClH}_{2} \mathrm{O}\right] .5 \mathrm{H}_{2} \mathrm{O}$ & 8-[Cd (Cefepime) $\left.\mathrm{OHH}_{2} \mathrm{O}\right] \mathrm{OH}$ \\
\hline 9- $\left.[\mathrm{Cu} \text { (Cefepime })_{3}\right] \mathrm{Cl}_{2} \cdot \mathrm{OH}$ & 10- $\left[\mathrm{Mn}_{2}(\text { Cefepime })_{3}(\mathrm{OH})_{2}\left(\mathrm{H}_{2} \mathrm{O}\right)_{2}\right](\mathrm{OH})_{3}$ \\
\hline 11- $\left[\mathrm{Hg}(\text { Cefepime })_{2}\right] \mathrm{Cl}_{2} \cdot 6 \mathrm{H}_{2} \mathrm{O}$ & 12- $\left[\mathrm{Cr}_{2}(\right.$ Cefepime $\left.)(\mathrm{OH})_{4}\left(\mathrm{H}_{2} \mathrm{O}\right)_{4}\right]$ OH. $\mathrm{H}_{2} \mathrm{O}$ \\
\hline 13- $\left[\mathrm{Co}_{2}(\right.$ Cefepime $\left.)(\mathrm{OH})_{3} \mathrm{H}_{2} \mathrm{O}\right](\mathrm{OH})$ & 14-[Fe (Cefepime) $\left.] \mathrm{Cl}_{2}\left(\mathrm{H}_{2} \mathrm{O}\right)_{2}\right]$ Cl. $3 \mathrm{H}_{2} \mathrm{O}$ \\
\hline 15-[Co $\mathrm{Cu}_{3}$ (Cefepime) $\left.\mathrm{Cl}_{7} \mathrm{H}_{2} \mathrm{O}\right] \mathrm{Cl} .3 \mathrm{H}_{2} \mathrm{O}$ & 16- $\left[\mathrm{Cu}_{4}(\right.$ Cefepime $\left.) \mathrm{Cl}_{5} \mathrm{H}_{2} \mathrm{O}\right] \mathrm{Cl} \cdot \mathrm{H}_{2} \mathrm{O}$ \\
\hline 17-[Ni (Cefepime) $\left.)_{2}\right] \mathrm{Cl}_{2} 6 \mathrm{H}_{2} \mathrm{O}$ & 18-[Fe Cu(Cefepime) $\left.\mathrm{Cl}_{4}\left(\mathrm{H}_{2} \mathrm{O}\right)_{2}\right] \mathrm{Cl} .6 \mathrm{H}_{2} \mathrm{O}$ \\
\hline 19-[Fe Ni(Cefepime $\left.)_{3} \mathrm{Cl}_{2}\right] \cdot \mathrm{Cl}_{3} \cdot 2 \mathrm{H}_{2} \mathrm{O}$ & 20- $[\mathrm{Fe}$ (Cefepime) $\left.] \mathrm{Cl}_{2}\left(\mathrm{H}_{2} \mathrm{O}\right)_{2}\right] \mathrm{Cl} .3 \mathrm{H}_{2} \mathrm{O}$ \\
\hline
\end{tabular}

\subsection{Antidiabetic}

The effects of Metallocephradines and Metallocefepimes on digestive enzymes were given in Table 6 and Figures (4-5). It was found that all Metallocephradinesacts as maltase, lactase sucrase, amylase and lipase inhibitors, except $\mathrm{Cu}$-cephradine (1:2) and mixed metal (Fe-Ni)-cephradine complexes did not show inhibitory effect on maltase. These results suggested that the octahedral Cr-cephradinecomplex (2:1) showed the highest inhibitory activity towards maltase activity. Also, $\mathrm{Mn}$ (II) and $\mathrm{Hg}$ (II)-cephradine complexes act as activators for lipase activity in comparison with the cephradine and the control.On the other hand, all Metallocefepimes act as maltase, lactase, sucrose and amylase inhibitors. So, the presence of metals caused a significant inhibition in comparison with cefepime and control.However, all Metallocefepimes act as lipase activators, except the octahedral Fe(III)- 
In Vitro Biological Screening for Antimicrobial, DNA Cleavage Anti-Diabetic, Antioxidant, AntiInflammatory and Antihaemolytic of Some Metallocephalosporins

cefepime-complex (1:3), the square planar $\mathrm{Cu}$ (II)-cefepime complexes (4:1) and the mixed metals $(\mathrm{Fe}-\mathrm{Ni}),(\mathrm{Fe}-\mathrm{Cu})$ and $(\mathrm{Co}-\mathrm{Cu})$-cefepime complexes act as inhibitors.

It was observed that $\mathrm{Cu}$-cephradine in 1:2 (M:L) and mixed metal (Fe-Ni)-cephradine in 1:1:1 (M:M:L) had slight effect on maltase activity and strong inhibitory effect on lactase, sucrase, amylase and lipase. However, lipase enzyme was activated by Mn-cephradine in 1:1 (M:L), Cd-cephradine in 2:1 (M:L), Cr (III), Co (II)-cefepime in 2:1 (M:L), Mn-cefepime in 2:3 (M:L), Fe (III), Ni (II), Zn (II), $\mathrm{Cd}$ (II)-cefepime in 1:1 (M:L), Ni-cefepime in 1:2 (M:L), $\mathrm{Cu}$ (II), $\mathrm{Hg}$ (II)-cefepime in 1:3(M:L) complexes, while maltase, lactase, sucrase and amylase enzymes were inhibited by these complexes. However, Cr (III), Fe (III), Zn (II), Cd (II)-cephradine complexes in 2:1(M:L), Co-cephradine in 1:3 (M:L), Ni-cephradine in 1:1 and 1:2 (M:L), Cu-cephradine in 3:1(M:L), (Fe-Cu)-cephradine in 1:2:2 (M:M:L) , (Fe-Co)-cephradine in 1:1:2 (M:M:L),Fe-cefepime in 1:3(M:L), Cu-cefepime in 4:1(M:L),

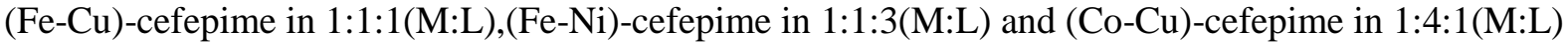
had strong inhibitory effect on maltase, lactase, sucrase, amylase and lipase activity. These results suggested that these Metallocephradines and Metallocefepimes showed its antidiabetic effect via inhibiting maltase, lactase, sucrase, amylase and lipase activity [55-56].

Table6. Effect of Metallocephradines and Metallocefepimeson digestive enzymes

\begin{tabular}{|c|c|c|c|c|c|}
\hline \multirow[t]{2}{*}{ Compound } & \multicolumn{5}{|c|}{ Digestive enzymes } \\
\hline & $\begin{array}{l}\text { Maltase } \\
\text { Activity } \\
\text { (IU) }\end{array}$ & \begin{tabular}{|l|} 
Lactase \\
Activity \\
(IU) \\
\end{tabular} & $\begin{array}{l}\text { Sucrase } \\
\text { Activity } \\
\text { (IU) }\end{array}$ & $\begin{array}{l}\text { Amylase } \\
\text { Activity } \\
\text { (IU) }\end{array}$ & $\begin{array}{l}\text { Lipase } \\
\text { Activity } \\
\text { (IU) }\end{array}$ \\
\hline Control $\mathrm{H}_{2} \mathrm{O}$ & 29.98 & 16.25 & 19.02 & 134.81 & 550 \\
\hline Control DMSO & 30.14 & 17.41 & 19.02 & 144.92 & 550 \\
\hline Cephradine & $30.11 \pm 0.1$ & $0.48 \pm 0.02$ & $0.47 \pm 0.1$ & $3.71 \pm 0.1$ & $600 \pm 0.06$ \\
\hline$\left[\mathrm{Cr}_{2}(\text { Cephradine })_{3}(\mathrm{OH})_{3} \mathrm{H}_{2} \mathrm{O}\right] 3 \mathrm{H}_{2} \mathrm{O}$ & $14.68 \pm 0.1$ & $0.49 \pm 0.02$ & $0.46 \pm 0.1$ & $3.89 \pm 0.1$ & $540 \pm 0.06$ \\
\hline$\left[\mathrm{Mn}(\right.$ Cephradine $\left.) \mathrm{Cl}\left(\mathrm{H}_{2} \mathrm{O}\right)_{3}\right] \mathrm{HCl} .2 \mathrm{H}_{2} \mathrm{O}$ & $27.21 \pm 0.02$ & $0.52 \pm 0.02$ & $0.57 \pm 0.08$ & $4.20 \pm 0.05$ & $690 \pm 0.08$ \\
\hline$\left[\mathrm{Fe}_{2}(\right.$ Cephradine $\left.) \mathrm{Cl}_{5}\left(\mathrm{H}_{2} \mathrm{O}\right)_{3}\right] \mathrm{H}_{2} \mathrm{O}$ & $27.52 \pm 0.03$ & $0.47 \pm 0.05$ & $0.49 \pm 0.08$ & $3.69 \pm 0.05$ & $495 \pm 0.08$ \\
\hline$\left[\mathrm{Co}(\text { Cephradine })_{3}\right] 2 \mathrm{HCl} . \mathrm{H}_{2} \mathrm{O}$ & $28.06 \pm 0.04$ & $0.56 \pm 0.06$ & $0.53 \pm 0.07$ & $3.93 \pm 0.1$ & $520 \pm 0.07$ \\
\hline$\left[\mathrm{Ni}\right.$ (Cephradine) $\left.\mathrm{Cl} \mathrm{H}_{2} \mathrm{O}\right] \mathrm{HCl} .3 \mathrm{H}_{2} \mathrm{O}$ & $25.60 \pm 0.05$ & $0.48 \pm 0.02$ & $0.46 \pm 0.07$ & $3.79 \pm 0.2$ & $385 \pm 0.05$ \\
\hline$\left[\mathrm{Ni}(\text { Cephradine })_{2}\right] 2 \mathrm{HCl}$ & $27.41 \pm 0.08$ & $0.52 \pm 0.07$ & $0.54 \pm 0.05$ & $3.98 \pm 0.06$ & $475 \pm 0.04$ \\
\hline$\left[\mathrm{Cu}(\text { Cephradine })_{2}\right] 2 \mathrm{HCl} .6 \mathrm{H}_{2} \mathrm{O}$ & $30.19 \pm 0.07$ & $0.53 \pm 0.01$ & $0.52 \pm 0.06$ & $4.03 \pm 0.05$ & $465 \pm 0.1$ \\
\hline$\left[\mathrm{Cu}_{3}(\right.$ Cephradine $\left.) \mathrm{Cl}_{5} \mathrm{H}_{2} \mathrm{O}\right] \mathrm{HCl}$ & $27.27 \pm 0.08$ & $0.48 \pm 0.08$ & $0.59 \pm 0.05$ & $4.02 \pm 0.07$ & $450 \pm 0.1$ \\
\hline$\left[\mathrm{Zn}_{2}\right.$ (Cephradine) $\left.\mathrm{Cl}_{3} \mathrm{H}_{2} \mathrm{O}\right] \mathrm{HCl} \cdot \mathrm{H}_{2} \mathrm{O}$ & $29.56 \pm 0.06$ & $0.38 \pm 0.07$ & $0.43 \pm 0.04$ & $3.80 \pm 0.08$ & $430 \pm 0.04$ \\
\hline$\left[\mathrm{Cd}_{2}(\right.$ Cephradine $\left.) \mathrm{Cl}_{3} \mathrm{H}_{2} \mathrm{O}\right] \mathrm{HCl} . \mathrm{H}_{2} \mathrm{O}$ & $28.31 \pm 0.05$ & $0.49 \pm 0.06$ & $0.51 \pm 0.1$ & $3.96 \pm 0.05$ & $455 \pm 0.04$ \\
\hline$\left[\mathrm{Hg}(\text { Cephradine })_{3}\right] 2 \mathrm{HCl} .6 \mathrm{H}_{2} \mathrm{O}$ & $29.80 \pm 0.1$ & $0.52 \pm 0.06$ & $0.49 \pm 0.2$ & $3.96 \pm 0.05$ & $585 \pm 0.05$ \\
\hline$\left.\left[\mathrm{Fe} \mathrm{Cu}_{2} \text { (Cephradine }\right)_{2} \mathrm{Cl}_{5} \mathrm{H}_{2} \mathrm{O}\right] 2 \mathrm{HCl} .3 \mathrm{H}_{2} \mathrm{O}$ & $28.13 \pm 0.07$ & $0.54 \pm 0.02$ & $0.61 \pm 0.1$ & $3.87 \pm 0.04$ & $410 \pm 0.05$ \\
\hline$\left[\mathrm{Fe} \mathrm{Co}(\text { Cephradine })_{2} \mathrm{Cl}_{3} \mathrm{H}_{2} \mathrm{O}\right] 2 \mathrm{HCl} .3 \mathrm{H}_{2} \mathrm{O}$ & $30.08 \pm 0.1$ & $0.49 \pm 0.03$ & $0.49 \pm 0.2$ & $4.05 \pm 0.04$ & $490 \pm 0.06$ \\
\hline$\left[\mathrm{Fe} \mathrm{Ni}\right.$ (Cephradine) $\left.\mathrm{Cl}_{4} 2 \mathrm{H}_{2} \mathrm{O}\right] \mathrm{HCl} .4 \mathrm{H}_{2} \mathrm{O}$ & $30.41 \pm 0.1$ & $0.48 \pm 0.03$ & $0.52 \pm 0.2$ & $4.25 \pm 0.1$ & $505 \pm 0.06$ \\
\hline Cefepime & $31.17 \pm 0.01$ & $0.48 \pm 0.02$ & $0.47 \pm 0.1$ & $3.73 \pm 0.1$ & $595 \pm 0.06$ \\
\hline$\left[\mathrm{Cr}_{2}\right.$ (Cefepime) $\left.(\mathrm{OH})_{4}\left(\mathrm{H}_{2} \mathrm{O}\right)_{4}\right]$ OH. $\mathrm{H}_{2} \mathrm{O}$ & $26.27 \pm 0.02$ & $0.51 \pm 0.03$ & $0.49 \pm 0.1$ & $3.84 \pm 0.2$ & $2115 \pm 0.05$ \\
\hline$\left[\mathrm{Mn}_{2}(\text { Cefepime })_{3}(\mathrm{OH})_{2}\left(\mathrm{H}_{2} \mathrm{O}\right)_{2}\right](\mathrm{OH})_{3}$ & $25.34 \pm 0.02$ & $0.46 \pm 0.02$ & $0.48 \pm 0.2$ & $3.80 \pm 0.08$ & $1975 \pm 0.04$ \\
\hline$\left.[\mathrm{Fe} \text { (Cefepime) })_{3}\right] \mathrm{Cl}_{3} .4 \mathrm{H}_{2} \mathrm{O}$ & $29.49 \pm 0.03$ & $0.51 \pm 0.04$ & $0.51 \pm 0.2$ & $4.08 \pm 0.08$ & $485 \pm 0.06$ \\
\hline$[\mathrm{Fe}$ (Cefepime) $\left.] \mathrm{Cl}_{2}\left(\mathrm{H}_{2} \mathrm{O}\right)_{2}\right]$ Cl. $3 \mathrm{H}_{2} \mathrm{O}$ & $27.01 \pm 0.05$ & $0.45 \pm 0.02$ & $0.48 \pm 0.09$ & $4.01 \pm 0.06$ & $615 \pm 0.07$ \\
\hline$\left[\mathrm{Co}_{2}\right.$ (Cefepime) $\left.(\mathrm{OH})_{3} \mathrm{H}_{2} \mathrm{O}\right] \mathrm{OH}$ & $27.33 \pm 0.01$ & $0.49 \pm 0.04$ & $0.52 \pm 0.09$ & $3.85 \pm 0.05$ & $1105 \pm 0.08$ \\
\hline [Ni (Cefepime) $\left.\mathrm{Cl} \mathrm{H}_{2} \mathrm{O}\right] \mathrm{Cl}_{.5} \mathrm{H}_{2} \mathrm{O}$ & $28.42 \pm 0.01$ & $0.49 \pm 0.04$ & $0.49 \pm 0.09$ & $3.73 \pm 0.05$ & $840 \pm 0.06$ \\
\hline$\left.[\mathrm{Ni} \text { (Cefepime) })_{2}\right] \mathrm{Cl}_{2} \cdot 6 \mathrm{H}_{2} \mathrm{O}$ & $24.65 \pm 0.03$ & $0.48 \pm 0.01$ & $0.51 \pm 0.07$ & $3.99 \pm 0.08$ & $575 \pm 0.04$ \\
\hline [Zn(Cefepime) $\left.\mathrm{Cl} \mathrm{H}_{2} \mathrm{O}\right] .5 \mathrm{H}_{2} \mathrm{O}$ & $26.27 \pm 0.02$ & $0.47 \pm 0.07$ & $0.49 \pm 0.1$ & $3.82 \pm 0.09$ & $1785 \pm 0.06$ \\
\hline$\left[\mathrm{Cd}\right.$ (Cefepime) $\left.\mathrm{OH} \mathrm{H}_{2} \mathrm{O}\right] \mathrm{OH}$ & $26.79 \pm 0.02$ & $0.45 \pm 0.07$ & $0.50 \pm 0.1$ & $3.97 \pm 0.1$ & $2100 \pm 0.06$ \\
\hline$\left[\mathrm{Hg}(\text { Cefepime })_{2}\right] \mathrm{Cl}_{2} \cdot 6 \mathrm{H}_{2} \mathrm{O}$ & $29.61 \pm 0.01$ & $0.50 \pm 0.07$ & $0.47 \pm 0.08$ & $3.85 \pm 0.1$ & $1685 \pm 0.1$ \\
\hline$\left[\mathrm{Fe} \mathrm{Cu}(\right.$ Cefepime $\left.) \mathrm{Cl}_{4}\left(\mathrm{H}_{2} \mathrm{O}\right)_{2}\right] \mathrm{Cl}_{6} 6 \mathrm{H}_{2} \mathrm{O}$ & $27.68 \pm 0.01$ & $0.46 \pm 0.06$ & $0.48 \pm 0.08$ & $3.93 \pm 0.05$ & $470 \pm 0.1$ \\
\hline$\left.[\mathrm{Fe} \mathrm{Ni(Cefepime})_{3} \mathrm{Cl}_{2}\right] \mathrm{Cl}_{3} \cdot 2 \mathrm{H}_{2} \mathrm{O}$ & $27.26 \pm 0.01$ & $0.39 \pm 0.02$ & $0.51 \pm 0.09$ & $3.93 \pm 0.05$ & $525 \pm 0.03$ \\
\hline$\left[\mathrm{Co} \mathrm{Cu}_{3}\right.$ (Cefepime) $\left.\mathrm{Cl}_{7} \mathrm{H}_{2} \mathrm{O}\right] \mathrm{Cl}$. & $25.37 \pm 0.02$ & $0.99 \pm 0.02$ & $0.54 \pm 0.09$ & $4.03 \pm 0.05$ & $515 \pm 0.03$ \\
\hline
\end{tabular}

Results are represented as mean $\pm S D$

$\%=[($ test-control $) /$ control $] * 100$ 


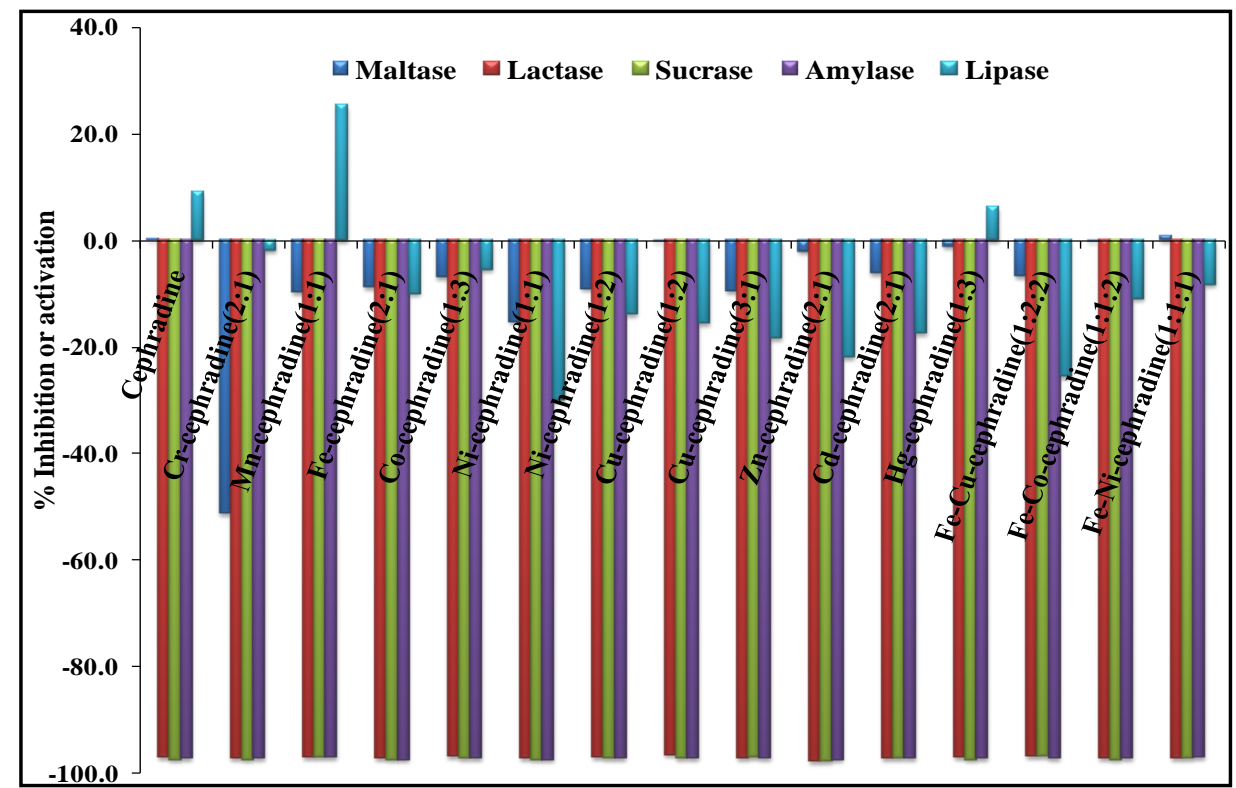

Figure4. The effect of Metallocephradines on the activity of maltase, lactase, sucrase, amylase, and lipase

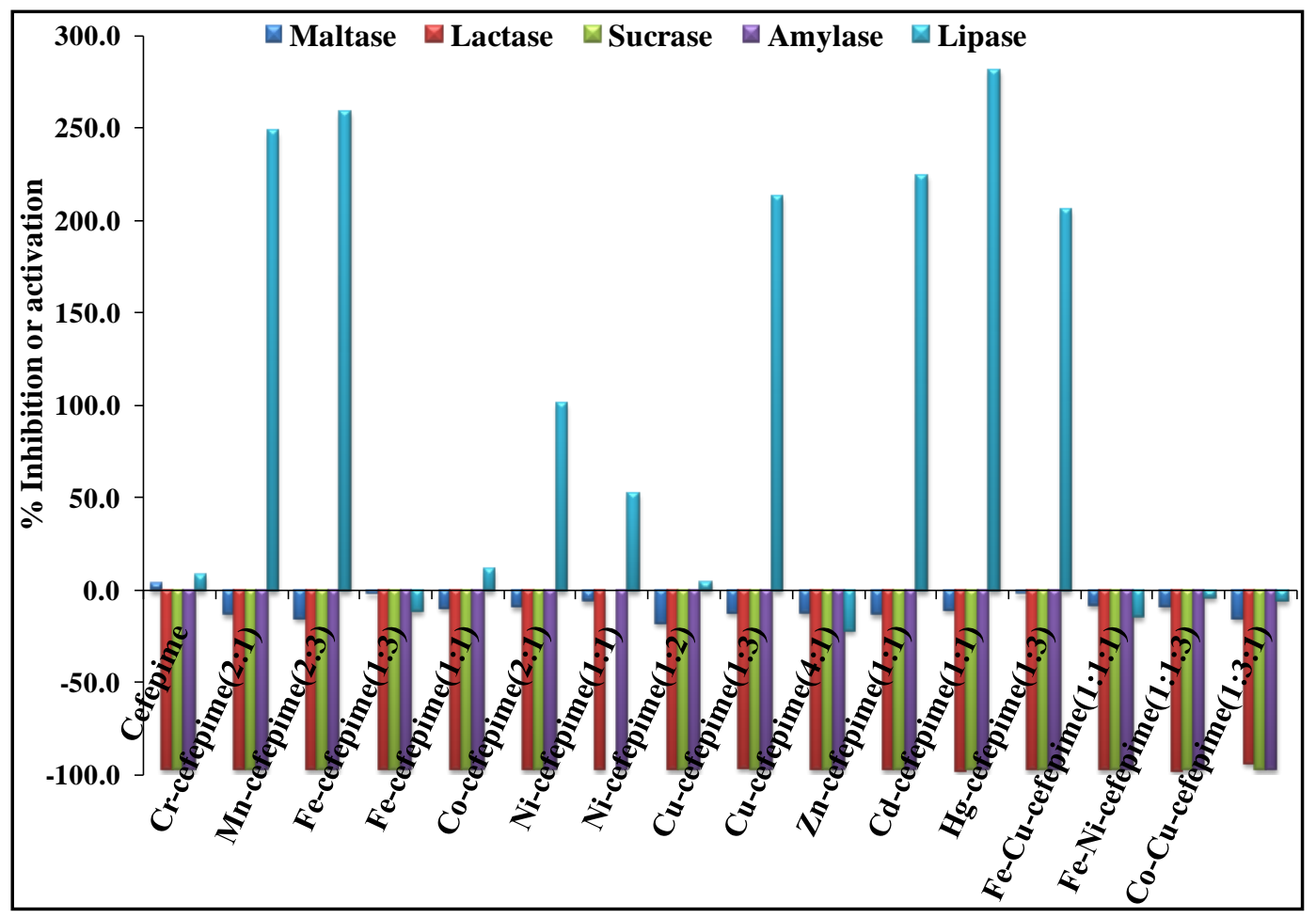

Figure5. The effect of Metallocefepimes on maltase, lactase, sucrase, amylase, and lipase activity

\subsection{Antioxidant}

Assessment of antioxidant activities showed that the activity of the complexes in scavenging of free radical DPPH is fairly good but less than ascorbic acid (113.91\%) as positive control in Table 7, except Fe-cephradine complex in 2:1(M:L), which showed higher activity than ascorbic acid (124.90\%), could be due to the coordination of the two $\mathrm{Fe}(\mathrm{III})$ ions with cephradine in a stable five membered ring in $\mathrm{O}_{\mathrm{h}}$ geometry, where the first $\mathrm{Fe}$ (III) ion is coordinated to the the carboxylate group and the adjacent nitrogen atom with a stable five membered ring and the second $\mathrm{Fe}(\mathrm{III})$ ion is attached to the nitrogen atom of the group $-\mathrm{C}=\mathrm{N}-\mathrm{O}$ and $\mathrm{NH}_{2}$ with a stable five membered ring.

Among the examined metal complexes, $\mathrm{Cr}$ (III), Co (II), Ni (II) in 1:2 (M:L) molar ratio Cu (II), Zn (II), Cd (II) and the mixed metal [Fe (III)-Co (II)], [Fe (III)-Ni (II)] and [Fe (III)-Cu (II)]-cephradine complexes have exhibitedgood scavenging activity, where as Mn (II), Ni (II) in 1:1(M:L) molar ratio and $\mathrm{Hg}$ (II)-cephradine complexes have shown moderate activity. From such results, we can conclude that the bimetallic, tetra-metallic and mixed metal cephradine complexes have exhibited higher 
In Vitro Biological Sceening for Antimicrobial, DNA Cleavageanti-Diabetic, Antioxidant, Anti-Inflamm otary and Antihaemolytic of Some Metallocephalosporins

antioxidant than mono-metallic $\mathrm{Mn}$ (II), Ni (II) and Hg (II) cephradine complexes in 1:1(M:L) molar ratio could be due to as the number of chelating ring increased, the stability of the formed metal complexes was increased, $\mathrm{Cu}$ (II) in 1:2 (M:L) molar ratio showed higher antioxidant activity than $\mathrm{Ni}$ (II), $\mathrm{Mn}$ (II) and $\mathrm{Hg}$ (II) in 1:1 (M:L) molar ratio due to the higher stability of the formed complexes in 1:2 (M:L) molar ratio than metal complexes in 1:1(M:L) molar ratio.

All the metal complexes have exhibited higher scavenging activity than cephradine. The marked antioxidant activity of the metal complexes in comparison to cephradine could be due to the coordination of metal with carboxylate ion vai deprotonation and the adjacent nitrogen atom. Hence, hydrogen of carboxylate ion could be easily donated to the DPPH free radical and convert itself into the stable free radical.

However, DPPH scavenging activity of Metallocefepimes was fairly good but less than cefepime and ascorbic acid aspositive control. Significant activity was found in both $\mathrm{Zn}$ (II) and Cd (II)-cefepime complexes in 1:1(M: L) molar ratio. Also, among the tested metal complexes, $\mathrm{Cu}$ (II) in 1:3 molar ratio, Fe (III) in 1:1 molar ratio, Co (II), $\mathrm{Zn}$ (II), Cd (II) and the mixed metal [(Co (II)-Cu (II)] have exhibited good antioxidant activity compared with ascorbic acid and cefepime . However $\mathrm{Cr}$ (III), Mn (II), Fe (III) in 1:3(M:L) molar ratio, Ni (II) in 1:1(M:L) molar ratio, $\mathrm{Hg}$ (II) and the mixed metals of $\mathrm{Fe}$ (III) with $\mathrm{Ni}$ (II) or $\mathrm{Cu}$ (II) have moderate antioxidant activity, while Ni (II)-cefepime complex in 1:2 (M:L) molar ratio act as aprooxidant.

\subsection{DPPH Reductase Activity}

The results of spectrophotometric investigation of redox interactionof oxidized form of Cytochrome c with cephradine, cefepime and their metal complexes are given in Table 7. It was found that cephradine and its metal complexes have a moderate DPPH-reductase activity, which is less than ascorbic acid as a positive control. Fe (III), Co (II), [Fe (III)-Co (II)] and [Fe (III)-Ni (II)] cephradine complexes showed the highest rate of cytochrome $\mathrm{c}$ reduction and also antioxidant activity in comparison with the parent antibiotic but less than the ascorbic acid, this may be attributed to the highest stability of these metal complexes.

It was found that Metallocefepimes gave DPPH reductase activity but less than ascorbic acid as a positive control. Among the examined metal complexes, it was observed that $\mathrm{Cu}$-cefepime complex in 1:3 (M:L) molar ratio exhibited higher DPPH reductase activity than cefepime, this may be due to the coordination of $\mathrm{Cu}$ (II) to the carboxylate group and the adjacent nitrogen atom with a stable five membered ring in octahedral geometry.

Table7. The effect of Metallocephradines and Metallocefepimes on antioxidant and DPPH reductase activity

\begin{tabular}{|c|c|c|}
\hline Compound & $\begin{array}{l}\text { DPPH } \\
\text { activity \% }\end{array}$ & $\begin{array}{l}\text { DPPH reductase } \\
\text { activity (IU) }\end{array}$ \\
\hline Vitamine $\mathbf{C}$ & $113.91 \pm \mathbf{0 . 0 0 1}$ & $0.003 \pm 0.03$ \\
\hline Cephradine & $42.12 \pm 0.01$ & $0.014 \pm 0.01$ \\
\hline$\left[\mathrm{Cr}_{2}(\text { Cephradine })_{3}(\mathrm{OH})_{3} \mathrm{H}_{2} \mathrm{O}\right] 3 \mathrm{H}_{2} \mathrm{O}$ & $61.53 \pm 0.0007$ & $0.0123 \pm 0.1$ \\
\hline$\left[\mathrm{Mn}(\mathrm{Cephradine}) \mathrm{Cl}\left(\mathrm{H}_{2} \mathrm{O}\right)_{3}\right] \mathrm{HCl} \cdot 2 \mathrm{H}_{2} \mathrm{O}$ & $58.24 \pm 0.008$ & $0.0129 \pm 0.09$ \\
\hline$\left[\mathrm{Fe}_{2}(\right.$ Cephradine $\left.) \mathrm{Cl}_{5}\left(\mathrm{H}_{2} \mathrm{O}\right)_{3}\right] \mathrm{H}_{2} \mathrm{O}$ & $124.90 \pm 0.004$ & $0.0116 \pm 0.18$ \\
\hline$\left[\mathrm{Co}(\mathrm{Cephradine})_{3}\right] 2 \mathrm{HCl} . \mathrm{H}_{2} \mathrm{O}$ & $73.9 \pm 0.007$ & $0.0119 \pm 0.2$ \\
\hline$\left[\mathrm{Ni}\right.$ (Cephradine) $\left.\mathrm{ClH}_{2} \mathrm{O}\right] \mathrm{HCl} .3 \mathrm{H}_{2} \mathrm{O}$ & $47.25 \pm 0.002$ & $0.0128 \pm 0.003$ \\
\hline$\left[\mathrm{Ni}(\text { Cephradine })_{2}\right] 2 \mathrm{HCl}$ & $74.72 \pm 0.003$ & $0.0131 \pm 0.02$ \\
\hline$\left.[\mathrm{Cu} \text { (Cephradine })_{2}\right] 2 \mathrm{HCl} .6 \mathrm{H}_{2} \mathrm{O}$ & $83.51 \pm 0.004$ & $0.0131 \pm 0.02$ \\
\hline$\left[\mathrm{Cu}_{3}(\right.$ Cephradine $\left.) \mathrm{Cl}_{5} \mathrm{H}_{2} \mathrm{O}\right] \mathrm{HCl}$ & $81.68 \pm 0.001$ & $0.0124 \pm 0.0007$ \\
\hline$\left[\mathrm{Zn}_{2}\right.$ (Cephradine) $\left.\mathrm{Cl}_{3} \mathrm{H}_{2} \mathrm{O}\right] \mathrm{HCl} \cdot \mathrm{H}_{2} \mathrm{O}$ & $80.95 \pm 0.007$ & $0.0137 \pm 0.10$ \\
\hline$\left[\mathrm{Cd}_{2}(\right.$ Cephradine $\left.) \mathrm{Cl}_{3} \mathrm{H}_{2} \mathrm{O}\right] \mathrm{HCl} \cdot \mathrm{H}_{2} \mathrm{O}$ & $81.61 \pm 0.00$ & $0.0131 \pm 0.02$ \\
\hline$\left[\mathrm{Hg}(\mathrm{Cephradine})_{3}\right] 2 \mathrm{HCl} .6 \mathrm{H}_{2} \mathrm{O}$ & $57.50 \pm 0.0092$ & $0.0125 \pm 0.07$ \\
\hline$\left[\mathrm{Fe} \mathrm{Cu}_{2}(\mathrm{Cephradine})_{2} \mathrm{Cl}_{5} \mathrm{H}_{2} \mathrm{O}\right] 2 \mathrm{HCl} .3 \mathrm{H}_{2} \mathrm{O}$ & $60.43 \pm 0.018$ & $0.0128 \pm 0.05$ \\
\hline$\left[\mathrm{Fe} \mathrm{Co}(\text { Cephradine })_{2} \mathrm{Cl}_{3} \mathrm{H}_{2} \mathrm{O}\right] 2 \mathrm{HCl} .3 \mathrm{H}_{2} \mathrm{O}$ & $77.65 \pm 0.002$ & $0.0117 \pm 0.18$ \\
\hline$\left[\mathrm{Fe} \mathrm{Ni}\right.$ (Cephradine) $\left.\mathrm{Cl}_{4} 2 \mathrm{H}_{2} \mathrm{O}\right] \mathrm{HCl} .4 \mathrm{H}_{2} \mathrm{O}$ & $83.51 \pm 0.002$ & $0.0105 \pm 0.07$ \\
\hline Cefepime & $170.6 \pm 0.004$ & $0.0110 \pm 0.06$ \\
\hline$\left[\mathrm{Cr}_{2}(\right.$ Cefepime $\left.)(\mathrm{OH})_{4}\left(\mathrm{H}_{2} \mathrm{O}\right)_{4}\right]$ OH. $\mathrm{H}_{2} \mathrm{O}$ & $60.8 \pm 0.0007$ & $0.0123 \pm 0.14$ \\
\hline
\end{tabular}

Continued Table 7 


\begin{tabular}{|l|l|l|}
\hline$\left[\mathrm{Mn}_{2}(\text { Cefepime })_{3}(\mathrm{OH})_{2}\left(\mathrm{H}_{2} \mathrm{O}\right)_{2}\right](\mathrm{OH})_{3}$ & $50.2 \pm 0.01$ & $0.0128 \pm 0.07$ \\
\hline$\left[\mathrm{Fe}(\text { Cefepime })_{3}\right] \mathrm{Cl}_{3} \cdot 4 \mathrm{H}_{2} \mathrm{O}$ & $67.7 \pm 0.01$ & $0.0118 \pm 0.02$ \\
\hline$[\mathrm{Fe}($ Cefepime $\left.)] \mathrm{Cl}_{2}\left(\mathrm{H}_{2} \mathrm{O}\right)_{2}\right] \mathrm{Cl} .3 \mathrm{H}_{2} \mathrm{O}$ & $84.9 \pm 0.009$ & $0.0112 \pm 0.009$ \\
\hline$\left[\mathrm{Co}_{2}(\right.$ Cefepime $\left.)(\mathrm{OH})_{3} \mathrm{H}_{2} \mathrm{O}\right] \mathrm{OH}$ & $79.8 \pm 0.006$ & $0.0132 \pm 0.004$ \\
\hline$\left[\mathrm{Ni}(\right.$ Cefepime $\left.) \mathrm{ClH}_{2} \mathrm{O}\right] \mathrm{Cl} .5 \mathrm{H}_{2} \mathrm{O}$ & $52.7 \pm 0.003$ & $0.0130 \pm 0.04$ \\
\hline$\left[\mathrm{Ni}(\text { Cefepime })_{2}\right] \mathrm{Cl}_{2} \cdot 6 \mathrm{H}_{2} \mathrm{O}$ & $0.7 \pm 0.07$ & $0.0134 \pm 0.084$ \\
\hline$\left[\mathrm{Cu}(\text { Cefepime })_{3}\right] \mathrm{Cl}_{2} \cdot \mathrm{OH}$ & $74.3 \pm 0.011$ & $0.006 \pm 0.73$ \\
\hline$\left[\mathrm{Zn}(\right.$ Cefepime $\left.) \mathrm{ClH}_{2} \mathrm{O}\right] .5 \mathrm{H}_{2} \mathrm{O}$ & $82.4 \pm 0.005$ & $0.0130 \pm 0.006$ \\
\hline$\left[\mathrm{Cd}(\right.$ Cefepime $\left.) \mathrm{OHH}_{2} \mathrm{O}\right] \mathrm{OH}$ & $100.7 \pm 0.015$ & $0.0122 \pm 0.05$ \\
\hline$\left[\mathrm{Hg}(\text { Cefepime })_{2}\right] \mathrm{Cl}_{2} \cdot 6 \mathrm{H}_{2} \mathrm{O}$ & $57.8 \pm 0.0007$ & $0.0124 \pm 0.24$ \\
\hline$\left[\mathrm{Fe} \mathrm{Cu}(\right.$ Cefepime $\left.) \mathrm{Cl}_{4}\left(\mathrm{H}_{2} \mathrm{O}\right)_{2}\right] \mathrm{Cl} \cdot 6 \mathrm{H}_{2} \mathrm{O}$ & $61.5 \pm 0.03$ & $0.0115 \pm 0.11$ \\
\hline$\left[\mathrm{Fe} \mathrm{Ni}(\text { Cefepime })_{3} \mathrm{Cl}_{2}\right] \mathrm{Cl}_{3} \cdot 2 \mathrm{H}_{2} \mathrm{O}$ & $65.2 \pm 0.01$ & $0.0131 \pm 0.001$ \\
\hline$\left[\mathrm{Co} \mathrm{Cu}(\right.$ Cefepime $\left.) \mathrm{Cl}_{7} \mathrm{H}_{2} \mathrm{O}\right] \mathrm{Cl} \cdot 3 \mathrm{H}_{2} \mathrm{O}$ & $74.3 \pm 0.001$ & $0.01236 \pm 0.019$ \\
\hline
\end{tabular}

Results are represented as mean $\pm S D$

\subsection{Anti-Inflammotry}

The reduction of nitric oxide radical by cephradine and its metal complexes were illustrated in Table 8. The maximum nitric oxide scavenging activity of octahedral Fe (III)-cephradine in 2:1(M:L) molar ratio was found to be $214.72 \%$, this may be attributed to the coordination of the two $\mathrm{Fe}$ (III) ions with cephradine in a stable five membered ring in $\mathrm{O}_{\mathrm{h}}$ geometry, where the first $\mathrm{Fe}$ (III) ion is coordinated to the carboxylate group and the adjacent nitrogen atom with a stable five membered ring and the second $\mathrm{Fe}$ (III) ion is attached to the nitrogen atom of the group $-\mathrm{C}=\mathrm{N}-\mathrm{O}$ and $\mathrm{NH}_{2}$ with a stable five membered ring.Also, $\mathrm{Hg}$ (II), [Fe (III)-Ni (II)], [Fe (III)-Co (II)], [Fe (III)-Cu (II)], Co (II) and $\mathrm{Cu}$ (II) in $1: 2$ and 3:1(M:L) molar ratio cephradine complexes have exhibited good nitric oxide scavenging activity as follow $147.20,129.94,101.01,78.68,71.57$ and $76.14 \%$, respectively in comparison with cephradine. However,Cr (III), Mn (II) and Ni (II) in 1:2 (M:1) molar ratio cephradine complexes have moderate NO-scavenging activity, while $\mathrm{Ni}$ (II) in 1:1(M:L) molar ratio, $\mathrm{Zn}$ (II) and $\mathrm{Cd}$ (II) cephradine complexes have NO-scavenging activity less than the parent antibiotic.

It was observed that all synthesized Metallocefepimes have NO-scavenging activity less than cefepime. Among the examined Metallocefepimes, $\mathrm{Cu}$ (II)-cefepime complex in 4:1(M:L) molar ratio gave the highest NO-scavenging activity, however, $\mathrm{Cr}(\mathrm{III}), \mathrm{Fe}(\mathrm{III})$ in 1:1 and 1:3(M:L) molar ratio, $\mathrm{Cu}(\mathrm{II})$ in $1: 3(\mathrm{M}: \mathrm{L})$ molar ratio, $[\mathrm{Fe}(\mathrm{III})-\mathrm{Cu}(\mathrm{II})]$ and $[\mathrm{Co}(\mathrm{II})-\mathrm{Cu}(\mathrm{II})]$ cefepime complexes gave a good NO-scavenging activity as follow 76.14, 84.26, 95.43, 72.0, 82.74 and $92.38 \%$, respectively. So, these complexes can be used in vascular regulation, improvement of immune response and prevent from apoptosis.However, Mn (II), Co (II), Ni (II) in 1:1 (M:L) molar ratio, $\mathrm{Hg}$ (II) and [Fe (III)-Ni (II)] cefepime complexes have moderate scavenging activity, 65.0, 47.71, 48.22, 56.34 and $55.83 \%$, respectively, while Ni (II) in 1:2 (M:L) molar ratio, Zn (II) and Cd (II) cefepime complexes have the least NO-scavenging activity.

\subsection{Anti Hemolytic Effect}

The lysosomal enzymes released during inflammation produce a variety of disorders. The extra cellular activity of these enzymes is said to be related to acute or chronic inflammation. The non steroidal anti-inflammatory drugs act either by inhibiting these lysosomal enzymes or by stabilizing the lysosomal membrane. Stabilization of lysosomal membrane is importantin limiting the inflammatory response by preventing the release of lysosomal constituents ofactivated neutrophil such as bactericidal enzymes and proteases, which cause further tissueinflammation and damage upon extra cellular release. Since HRBC membrane are similar to lysosomal membrane components, the prevention of hypotonicity induced HRBC membrane lyses is taken as a measure of antiinflammatory activity [33].

Metallocephradines andMetallocefepimes were examined for in vitro anti-inflammatoryactivity and toxicity by HRBC membrane stabilization method, Table 7. Metallo-cephradine showed significant anti-inflammatory activity and safe, where the hemolysis index $<5 \%$ in a concentration dependent manner, except $\mathrm{Ni}$ (II)-cephradine complex in 1:1 (M:L) ratio and $\mathrm{Cr}$ (III)-cefepime complex in 2:1 (M:L) ratio exhibited toxicity (hemolysis index $>5 \%$ ). 
In Vitro Biological Sceening for Antimicrobial, DNA Cleavageanti-Diabetic, Antioxidant, Anti-Inflamm otary and Antihaemolytic of Some Metallocephalosporins

Table8. Hemolysis index, concentration and antihaemolytic activity of Metallocephradines and Metallocefepimes

\begin{tabular}{|c|c|c|c|c|}
\hline Compound & $\begin{array}{l}\text { NO } \\
\text { scavenging } \\
\text { activity } \%\end{array}$ & $\begin{array}{l}\text { Hemolysis } \\
\text { index \% }\end{array}$ & $\begin{array}{l}\text { Concentration } \\
\mu \mathrm{mol}\end{array}$ & $\begin{array}{l}\text { Antihaemolytic } \\
\text { activity } \%\end{array}$ \\
\hline Cephradine & $48.87 \pm 0.00$ & -3.5 & 2.86 & 103.5 \\
\hline$\left[\mathrm{Cr}_{2}(\text { Cephradine })_{3}(\mathrm{OH})_{3} \mathrm{H}_{2} \mathrm{O}\right] 3 \mathrm{H}_{2} \mathrm{O}$ & $59.39 \pm 0.04$ & 4.3 & 0.007 & 95.7 \\
\hline$\left[\mathrm{Mn}(\right.$ Cephradine $\left.) \mathrm{Cl}\left(\mathrm{H}_{2} \mathrm{O}\right)_{3}\right] \mathrm{HCl} .2 \mathrm{H}_{2} \mathrm{O}$ & $55.32 \pm 0.002$ & -4.7 & 0.17 & 104.7 \\
\hline$\left[\mathrm{Fe}_{2}(\right.$ Cephradine $\left.) \mathrm{Cl}_{5}\left(\mathrm{H}_{2} \mathrm{O}\right)_{3}\right] \mathrm{H}_{2} \mathrm{O}$ & $214.72 \pm 0.0028$ & -4.3 & 0.004 & 104.3 \\
\hline$\left[\mathrm{Co}(\text { Cephradine })_{3}\right] 2 \mathrm{HCl} . \mathrm{H}_{2} \mathrm{O}$ & $78.68 \pm 0.002$ & -3.5 & 0.41 & 103.5 \\
\hline$\left[\mathrm{Ni}\left(\right.\right.$ Cephradine) $\left.\mathrm{Cl} \mathrm{H}_{2} \mathrm{O}\right] \mathrm{HCl} .3 \mathrm{H}_{2} \mathrm{O}$ & $37.56 \pm 0.0007$ & 1.3 & 0.018 & 98.7 \\
\hline$\left[\mathrm{Ni}(\text { Cephradine })_{2}\right] 2 \mathrm{HCl}$ & $49.23 \pm 0.004$ & 7.05 & 0.120 & 92.5 \\
\hline$\left.[\mathrm{Cu} \text { (Cephradine })_{2}\right] 2 \mathrm{HCl} .6 \mathrm{H}_{2} \mathrm{O}$ & $71.57 \pm 0.002$ & -14.7 & 0.01 & 114.7 \\
\hline$\left[\mathrm{Cu}_{3}(\right.$ Cephradine $\left.) \mathrm{Cl}_{5} \mathrm{H}_{2} \mathrm{O}\right] \mathrm{HCl}$ & $76.14 \pm 0.012$ & -1.1 & 0.129 & 101.1 \\
\hline$\left[\mathrm{Zn}_{2}\right.$ (Cephradine) $\left.\mathrm{Cl}_{3} \mathrm{H}_{2} \mathrm{O}\right] \mathrm{HCl} \cdot \mathrm{H}_{2} \mathrm{O}$ & $41.11 \pm 0.014$ & -1.3 & 0.015 & 101.3 \\
\hline$\left[\mathrm{Cd}_{2}(\right.$ Cephradine $\left.) \mathrm{Cl}_{3} \mathrm{H}_{2} \mathrm{O}\right] \mathrm{HCl} \cdot \mathrm{H}_{2} \mathrm{O}$ & $47.71 \pm 0.002$ & 1.3 & 0.013 & 98.7 \\
\hline$\left[\mathrm{Hg}(\text { Cephradine })_{3}\right] 2 \mathrm{HCl} .6 \mathrm{H}_{2} \mathrm{O}$ & $126.39 \pm 0.002$ & 4.3 & 0.007 & 95.7 \\
\hline $\begin{array}{l}{\left[\mathrm{Fe} \mathrm{Cu}_{2}(\text { Cephradine })_{2} \mathrm{Cl}_{5} \mathrm{H}_{2} \mathrm{O}\right]} \\
2 \mathrm{HCl} .3 \mathrm{H}_{2} \mathrm{O}\end{array}$ & $101.01 \pm 0.002$ & 1.2 & 0.09 & 98.8 \\
\hline $\begin{array}{l}{\left[\mathrm{Fe} \mathrm{Co}(\text { Cephradine })_{2} \mathrm{Cl}_{3} \mathrm{H}_{2} \mathrm{O}\right]} \\
2 \mathrm{HCl} 3 \mathrm{H}_{2} \mathrm{O}\end{array}$ & $129.94 \pm 0.0007$ & -5.2 & 0.009 & 105.2 \\
\hline $\begin{array}{l}{\left[\mathrm{Fe} \mathrm{Ni}(\mathrm{Cephradine}) \mathrm{Cl}_{4} 2 \mathrm{H}_{2} \mathrm{O}\right]} \\
\mathrm{HCl} .4 \mathrm{H}_{2} \mathrm{O}\end{array}$ & $147.20 \pm 0.013$ & -9.2 & 0.013 & 109.2 \\
\hline Cefepime & $140.74 \pm 0.0007$ & -5.8 & 0.2 & 105.8 \\
\hline$\left[\mathrm{Cr}_{2}(\right.$ Cefepime $\left.)(\mathrm{OH})_{4}\left(\mathrm{H}_{2} \mathrm{O}\right)_{4}\right]$ OH. $\mathrm{H}_{2} \mathrm{O}$ & $76.14 \pm 0.026$ & 10.5 & 0.65 & 89.5 \\
\hline$\left[\mathrm{Mn}_{2}(\text { Cefepime })_{3}(\mathrm{OH})_{2}\left(\mathrm{H}_{2} \mathrm{O}\right)_{2}\right](\mathrm{OH})_{3}$ & $65.0 \pm 0.004$ & -9.2 & 0.005 & 90.8 \\
\hline$\left[\mathrm{Fe}(\text { Cefepime })_{3}\right] \mathrm{Cl}_{3} \cdot 4 \mathrm{H}_{2} \mathrm{O}$ & $84.26 \pm 0.0003$ & 3.5 & 0.06 & 96.5 \\
\hline$[\mathrm{Fe}($ Cefepime $\left.)] \mathrm{Cl}_{2}\left(\mathrm{H}_{2} \mathrm{O}\right)_{2}\right] \mathrm{Cl} .3 \mathrm{H}_{2} \mathrm{O}$ & $95.43 \pm 0.0007$ & -9.2 & 0.013 & 90.8 \\
\hline$\left[\mathrm{Co}_{2}(\right.$ Cefepime $\left.)(\mathrm{OH})_{3} \mathrm{H}_{2} \mathrm{O}\right] \mathrm{OH}$ & $47.71 \pm 0.017$ & -1.1 & 0.73 & 101.1 \\
\hline$\left[\mathrm{Ni}\right.$ (Cefepime) $\left.\mathrm{Cl} \mathrm{H}_{2} \mathrm{O}\right] \mathrm{Cl} .5 \mathrm{H}_{2} \mathrm{O}$ & $48.22 \pm 0.004$ & 1.1 & 0.006 & 98.9 \\
\hline$\left.[\mathrm{Ni} \text { (Cefepime) })_{2}\right] \mathrm{Cl}_{2} \cdot 6 \mathrm{H}_{2} \mathrm{O}$ & $1.01 \pm 0.012$ & -7.8 & 0.008 & 107.8 \\
\hline$\left[\mathrm{Cu}(\text { Cefepime })_{3}\right] \mathrm{Cl}_{2} . \mathrm{OH}$ & $72.0 \pm 0.014$ & -3.9 & 0.006 & 96.1 \\
\hline$\left[\mathrm{Zn}(\right.$ Cefepime $\left.) \mathrm{Cl} \mathrm{H}_{2} \mathrm{O}\right] .5 \mathrm{H}_{2} \mathrm{O}$ & $11.16 \pm 0.040$ & -4.7 & 0.68 & 104.7 \\
\hline$\left[\mathrm{Cd}(\right.$ Cefepime $\left.) \mathrm{OH} \mathrm{H} \mathrm{H}_{2} \mathrm{O}\right] \mathrm{OH}$ & $29.94 \pm 0.148$ & -3.9 & 0.015 & 103.9 \\
\hline$\left[\mathrm{Hg}(\text { Cefepime })_{2}\right] \mathrm{Cl}_{2} \cdot 6 \mathrm{H}_{2} \mathrm{O}$ & $56.34 \pm 0.022$ & -3.9 & 0.007 & 103.9 \\
\hline$\left[\mathrm{Fe} \mathrm{Cu}(\right.$ Cefepime $\left.) \mathrm{Cl}_{4}\left(\mathrm{H}_{2} \mathrm{O}\right)_{2}\right] \mathrm{Cl} .6 \mathrm{H}_{2} \mathrm{O}$ & $82.74 \pm 0.004$ & -7.6 & 0.005 & 107.6 \\
\hline$\left[\mathrm{Fe} \mathrm{Ni}(\text { Cefepime })_{3} \mathrm{Cl}_{2}\right] \mathrm{Cl}_{3} \cdot 2 \mathrm{H}_{2} \mathrm{O}$ & $55.83 \pm 0.0007$ & -6.5 & 0.005 & 106.5 \\
\hline$\left[\mathrm{Co} \mathrm{Cu}_{3}(\right.$ Cefepime $\left.) \mathrm{Cl}_{7} \mathrm{H}_{2} \mathrm{O}\right] \mathrm{Cl} .3 \mathrm{H}_{2} \mathrm{O}$ & $92.38 \pm 0.003$ & -11.8 & 0.009 & 111.8 \\
\hline
\end{tabular}

Hemolysis index $=(T-B /$ Emax $) * 100$

\section{REFERENCES}

[1] J. A. Dimasi, W. Hansen and H. G. Grabowski, The price of innovation: new estimates of drug developed costs, J. Health Economics, 22: 151-185 (2003).

[2] E. B. Holmgren, Theory of drug development, Chapman \& Hall/CRC, 1-2 (2008).

[3] P. C. A. Bruijnincx and P. J. Sadler, New trends for metal complexes with anticancer activity, Curr. Opin. Chem. Biol, 12: 197-206 (2008).

[4] T. W. Hambley, Metal-based therapeutics, Science 318: 1392-1393 (2007).

[5] S. J. Lippard and J. M. Beng, Principles of bioinorganic chemistry, University Science Books, Mile Valley, California, 1994.

[6] M. D. Hall, C. T. Dillon, M. Zhang, P. Beale, Z. Cai, B. Lai, A. P. J. Stampfl and T. W. Hambley, The cellular distribution and oxidation state of platinum (II) and platinum (IV) antitumour complexes in cancer cells, J. Biol. Inorg. Chem. 8: 726-732 (2003).

[7] B. S. Sekhon, Metalloantibiotics and antibiotic mimics - an overview, J. Pharm. Educ. Res, 1 (1): $1-20$ (2010).

[8] A. Kapoor, R. Kapoor, S. Singla, V. Singla and B. Joshi, Synergistic, antagonistic and toxic effects of metals on antibiotics as metalloantibiotics. Global. J. Pharm. Res, 1 (3): 277-289 (2012). 
[9] M. S. Masoud, A. E. Ali and N. M. Nasr, Chemistry, classification, pharmacokinetics, clinical uses and analysis of betalactam antibiotics: A review, J. Chemical \& Pharm. Res., 6 (11): 28-58 (2014).

[10] M. S. Masoud, D. A. Ghareeb, A. E. Ali and N. M. Nasr, Effect of some novel Metallocefepimes on neurotransmitter catalyzing enzymes, J. Chemical \& Pharm. Res., 6 (7):1-9 (2014).

[11] M.S. Masoud, A. E. Ali, D. A. Ghareeb and N. M. Nasr, Synthesis and characterization of cephradine metal complexes as Alzheimer disease therapeutic agent: An in vitro kinetic study on acetylcholinesterase and monoamine oxidase, J. Chemical \& Pharm. Res., 5 (12): 1325-1334 (2013).

[12] I. Pal, F. Basuli, and S. Bhattacharya, Thiosemicarbazone complexes of the platinum metals. A story of variable coordination modes, Proceedings of the Indian academy of sciences, Chem. Sci., 114 (4): 255-268 (2002).

[13] G. Kumar, D. Kumar, S. Devi, R. Verma and R Johari Synthesis, spectral characterization of biologically active compounds derived from oxalyldihydrazide and 5-tert-butyl-2-hydroxy-3-(3phenylpent-3-yl) benzaldehyde and their $\mathrm{Cu}$ (II), Ni (II) and Co (II) complexes, Int. J. Eng. Sci. Technol. 3: 1630-1635 (2011).

[14] M. Roxas, The role of enzyme supplementation in digestive disorders. Altern. Med. Rev., 13 (4), 307-314 (2008).

[15] S. R. Pattan, S. B. Pawar, S. S. Vetal, U. D. Gharate and S. B. Bhawar, The scope of metal complexes in drug deign-a review, Indian drugs, 49 (11): 1-12 (2012).

[16] H. Sakurai, A. Katoh, T. Kiss, T. Jakusch and M. Hattori, Metallo-allixinate complexes with anti-diabetic and anti-metabolic syndrome activities, Metallomics, 2: 670-682 (2010).

[17] N. Yasumatsu, Y. Yoshikawa, Y. Adachi and H. Sakurai, Antidiabetic copper (II)-picolinate: impact of the first transition metal in the metallopicolinate complexes, Bioorg Med Chem 15: 4917-4922 (2007).

[18] H. Sakurai, A. Katoh and Y. Yoshikawa, Chemistry and biochemistry of insulin mimeticvanadium and zinc complexes, trial for treatment of diabetes mellitus, Bull. Chem. Soc. Jpn. 79: 1645-1664 (2006).

[19] Y. Yoshikawa, M. Kondo, H. Sakurai and Y. Kojima A family of insulinomimetic zinc (II) complexes of amino ligands with $\mathrm{Zn}(\mathrm{Nn})(\mathrm{n}=3$ and 4$)$ coordination modes, J. Inorg. Biochem. 99: 1497-1503 (2005).

[20] Y. Yoshikawa, R. Hirata, H. Yasui and H. Sakurai Alpha-glucosidase inhibitory effect of antidiabetic metal ions and their complexes, Biochimie 91: 1339-1341 (2009).

[21] E. R. Milaeva, Metal-based antioxidants--potential therapeutic candidates for prevention the oxidative stress-related carcinogenesis: mini-review, Cur.r Top. Med. Chem. 11 (21): 2703-2713 (2011).

[22] S. K. Bharti and S. K. Singh, Metal based drugs: current use and future potential, Der. Pharmacia. Lettre. 1 (2): 39-51 (2009).

[23] S. B. Etcheverry, D. A. Barrio, A. M. Cortizo and P. A. M. Williams, Three new vanadyl (IV) complexes with non-steroidal anti-inflammatory drugs (ibuprofen, naproxen and tolmetin). Bioactivity on osteoblast-like cells in culture, J. Inorg. Biochem, 88 (1), 94-100 (2002).

[24] M. A. Zayed and S. M. Abdallah, Synthesis, characterization and electronic spectra of cefadroxil complexes of d-block elements. Spectrochim.Acta A 60: 2215-2224 (2004).

[25] Z. H. Chohan, Synthesis of cobalt (II) and nickel (II) complexes of ceclor (cefaclor) and preliminary experiments on their antibacterial character, Chem. Pharm. Bull. 39, 1578-1580 (1991).

[26] J. R. Anacona and C. C. Gil, Synthesis and antibacterial activity of cefoxitin metal complexes. Transition. Met. Chem. 30: 605-609 (2005).

[27] J. R. Anacona and A. Rodriguez, Synthesis and antibacterial activity of ceftriaxone metal complexes. Transition. Met. Chem. 30: 897-901(2005).

[28] M. S. Iqbal, A. R. Ahmed, M. Sabir and S. M. Asad, Preparation, characterization and biological evaluation of copper (II) and zinc (II) complexes with cephalexin, J. Pharm. Pharmacol. 51: 371375 (1999). 
[29] R. M. Yszczek, Thermal investigations of cefadroxil complexes with transition metals: coupled TG-DSC and TG-FTIR techniques. J. Therm. Anal. Calorim. 78, 473-486 (2004).

[30] S. H. Auda, Y. Mrestanic, D. H. Nies, C. Große and R.H. H. Neubert, Preparation, physico chemical characterization and biological evaluation of cefodizime metal ion complexes, J.Pharm.Pharmacology, 61: 1-6 (2009).

[31] H. Agwa, M. M. Aly and R. Bonaly, Isolation and characterization of two streptomyces species produced non polyenic antifungal agents. J. Union. Arab. Biol. 7: 62-82 (2000).

[32] J. H. Doughari Antimicrobial activity of Tamarindus indica Linn. Trop. J. Pharm. Res. 5 (2): 597-603 (2006).

[33] V. Rajendran and K. S. Lakshmi, In-vitro and in-vivo anti-inflammatory activity of leaves of Symplocoscochinchnensis (Lour) Moore ssplaurina. Bangladesh, J. Pharmacol. 3: 121-124 (2008).

[34] N. Raman, L Mitu, A. Sakthivel and M. S. S. Pandi, Studies on DNA cleavage and antimicrobial screening of transition metal complexes of 4-Aminoantipyrine derivatives of $\mathrm{N}_{2} \mathrm{O}_{2}$ type, J. Iran. Chem. Soc., 6(4): 738-748 (2009).

[35] R. C. Ogden and D. A. Adams, Electrophoresis in agarose and acrylamide gels. Meth. Enzymol. 152: $61-87$ (1987).

[36] J. R. Brody and S. E. Kern, Sodium boric acid: a tris-free, cooler conductive medium for DNA electrophoresis. Biotechniques 36 (2): 214-6 (2004).

[37] J. R. Brody and S. E. Kern, History and principles of conductive media for standard DNA electrophoresis. Anal. Biochem. Rev, 333 (1): 1-13 (2004).

[38] J. R. Brody and S. E. Kern, Ultra-fast high-resolution agarose electrophoresis of DNA and RNA using low-molarity conductive media, Biotechniques 37 (4): 598, 600- 602 (2004).

[39] A. Dahlqvist, Disaccharidases. In: Bergmeyer HU, Ed. Methods of enzymatic analysis. New York: Academic Press vol. 2: pp. 916-22 (1974).

[40] P. Bernfeld, Amylases, $\alpha$ and $\beta$. In: Colowick SP, Kaplan NO, Eds. Methods in enzymology. New York: Academic Press; vol. I: pp. 149-58 (1955).

[41] W. Rick, $\alpha$-Amylase. In: Bergmeyer HU, Ed. Methods of enzymatic analysis. New York: Academic Press; vol. 2: pp. 885-90 (1974).

[42] N. W. Tietz and E. A. Fiereck, A specific method for serum lipase determination, Clin. Chem. Acta.13: 352-358 (1966).

[43] C. M. L. Pathiranan and F. Shahidi, Antioxidant activity of commercial soft and hard wheat as triticum aestivum L. affected by gastric $\mathrm{pH}$ conditions, J. Agriculture \& Food. Chem., 53: 24332440 (2005).

[44] N. Z. Shaban, M. H. Helmy, M. A. R. El-Kersh and B. F. Mahmoud, Effects of Bacillus thuringiensis toxin on hepatic lipid peroxidation and free-radical scavengers in rats given alphatocopherol or acetylsalicylate, Comparative Biochem \& Physiology C. 135: 405-414 (2003).

[45] Y. S. Kun, Y. S. Jung and Y. A. Chul, Continuous spectrophotometric assay for NADPHcytochrome P450 reductase activity using 1, 1-Diphenyl-2-icrylhydrazyl, J. Biochem \& Molecular Biology, 37 (5): 629-633 (2004).

[46] S. M. Nabavi, M. A. Ebrahimzadeh, S. F. Nabavi, A. Hamidinia and A. R Bekhradnia. Determination of antioxidant activity, phenol and flavonoids content of parrotiapersica mey, Pharmacology. 2: 560-567 (2008).

[47] F. Arjmand, B. Mohani and S. Ahmad, Synthesis, antibacterial, antifungal activity and interaction of CT-DNA with a new benzimidazole derived $\mathrm{Cu}$ (II) complex, Eur. J. Med. Chem.40: 1103-1110 (2005).

[48] C. S. Allardyce, P. J. Dyson, D. J. Ellis and P. A. Salter, Synthesis and characterisation of some water soluble ruthenium (II)-arene complexes and an investigation of their antibiotic and antiviral properties, J. Organo. Chem. 668 (1-2): 35- 42 (2003).

[49] D. H. Petering, In metal ions in biological systems. In: Sigel, H.(Ed.). Marcel Dekker, New York (1973).

[50] K. S. Prasad, L. S. Kumar, S. C. Shekar, M. Prasad, and H. D.Revanasiddappa, Oxovanadium complexes with bidentate $\mathrm{N}$, O ligands: synthesis, characterization, DNA binding, nuclease activity and antimicrobial studies, J. Chem. Sci, 12: 1-10, (2011). 
[51] T. D. Thangadurai and K. Natarajan, Mixed ligand complexes of ruthenium (II) containing $\alpha, \beta-$ unsaturated- $\beta$-ketoamines and their antibacterial activity, Trans. Metal. Chem, 26 (4-5): 500-504 (2001).

[52] L. Liu, Y. L. Yu, C. Liu, X. T. Wang, X. D. Liu and L. Xie. Insulin deficiency induces abnormal increase in intestinal disaccharidase activities and expression under diabetic states, evidences from in vivo and in vitro study. Biochemical Pharmacology. 82: 1963-1970 (2011).

[53] G. Prativel, M. Pitie, J. Bernadou and B. Meunier, Mononuclear silylvinylidene rhodium complexes from silylalkynes: The SiMe3 migration as an alternative to the $[1,2]-\mathrm{H}$ Shift, Angew. Chem. Int. Ed. Eng. 30 (6): 700-702 (1991).

[54] A. M. Thomas, A. D. Naik, M. Nethaji, A. R. Chakravarty, Photo-induced DNA cleavage activity of ternary (N salicylidene-L methioninato) copper (II) complexes of phenanthrolinebases, Indian J. Chem. 43A (4): 691-700 (2004).

[55] S. A. Mohamed, A. S. Fahmy and H. A. Salah, Disaccharidase activities in camel small intestine: biochemical investigations of maltase-glucoamylase activity, Comparative.Biochem \& Physiology B, 146: 124-130 (2007).

[56] I. Kostova and S. Balkansky, Metal complexes of biologically active ligands as potential antioxidants, Curr. Med. Chem, 20 (36): 4508-4039 (2013). 